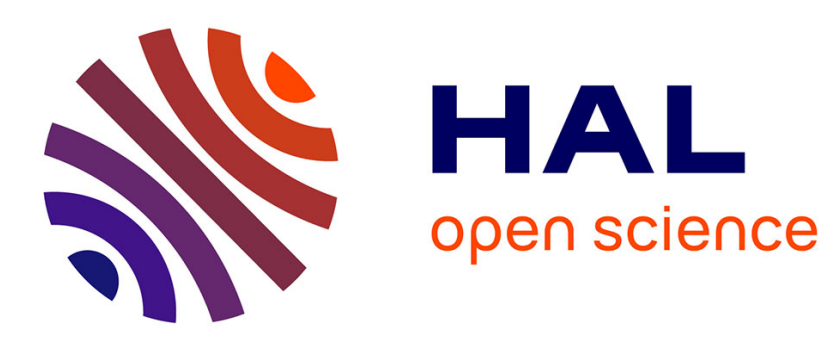

\title{
Fertility and Parental Labor-Force Participation: New Evidence from a Developing Country in the Balkans
}

Iva Trako

\section{To cite this version:}

Iva Trako. Fertility and Parental Labor-Force Participation: New Evidence from a Developing Country in the Balkans. 2016. halshs-01361443

\section{HAL Id: halshs-01361443 \\ https://shs.hal.science/halshs-01361443}

Preprint submitted on 7 Sep 2016

HAL is a multi-disciplinary open access archive for the deposit and dissemination of scientific research documents, whether they are published or not. The documents may come from teaching and research institutions in France or abroad, or from public or private research centers.
L'archive ouverte pluridisciplinaire HAL, est destinée au dépôt et à la diffusion de documents scientifiques de niveau recherche, publiés ou non, émanant des établissements d'enseignement et de recherche français ou étrangers, des laboratoires publics ou privés. 


\section{PARISSCHOOL OF ECONOMICS}

WORKING PAPER N² $2016-18$

Fertility and Parental Labor-Force Participation: New Evidence from a Developing Country in the Balkans

Iva Trako

JEL Codes: J13, J22, C26

Keywords: fertility, parental labor-force participation, instrumental variables

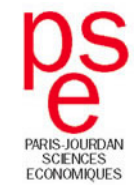




\title{
Fertility and Parental Labor-Force Participation: New Evidence from a Developing Country in the Balkans*
}

\author{
Iva Trako ${ }^{\dagger}$
}

May 31, 2016

\begin{abstract}
This paper examines the effect of fertility on parental labor-force participation in a developing country. In order to address the potential endogeneity in the fertility decision, I exploit Albanian parental preference for having sons as an exogenous source of variation. Using a repeated cross-section, I find that having an additional child has a positive and statistically significant effect on parental labor-force participation. IV estimates for mothers show that they increase labor supply, especially in terms of hours worked per week and the likelihood of working off-farm. Similarly, father's likelihood of working off-farm and having a second occupation increase as a consequence of further childbearing. The heterogeneity analysis suggests that this positive effect might be the result of two plausible mechanisms: childcare provided by non-parental adults in extended families and greater financial costs of feeding more children.
\end{abstract}

JEL Classification: J13, J22, C26

Keywords: fertility, parental labor-force participation, instrumental variables

* I would like to thank and recognize my advisor Karen Macours for her special support and guidance on the elaboration of this paper. Helpful comments and advice from Ekaterina Zhuravskaya, Marc Gurgand, Ivan Torre and Martin Rossi are also gratefully acknowledged. The views expressed in this paper are those of the author and do not necessarily represent those of Paris School of Economics. I am responsible for all remaining errors.

$\dagger$ Correspondence: Department of Economics, Paris School of Economics, 48 Boulevard Jourdan, 75014, Paris, Tel.: 00336645690 66, Email: ivatrako@gmail.com. 


\section{Introduction}

The relationship between fertility and parental labor supply has been of longstanding interest in economics. The majority of the empirical studies concerning the consequences of fertility in terms of the labour market outcomes focus on female labour supply and also most of them exist for developed countries (Browning, 1992). There are several reasons that might justify this particular interest. Firstly, during the second half of the 20th century developed countries have experienced a rising female labor supply along with delayed childbearing and fertility rate declines. Secondly, it is argued that the female-male labor-force differential or wage gap can be attributed to women's interruption of work due to the fact that they disproportionately face the responsibilities associated with childbearing and raising children (Goldin, 1990; Gronau, 1988; Korenman and Neumark, 1992).

However, less empirical evidence exits about the effect of fertility on parental labor supply for developing countries, where the setting for analyzing this relationship might be even more important for several reasons. First, in developing countries women are under-represented in higher proportions in the labor market and, therefore, primarily engaged in family activities (Mammen and Paxson, 2000). Second, the degree of heterogeneity in labor arrangements in developing countries reveals an additional dimension of inequality in labor outcomes. Evidence suggests that women are more likely to be engaged in the informal sector (i.e. unpaid family worker) of the labor market (Blunch et al., 2001). Third, since 1960 many developing countries have experienced a decline of 50 percent in total fertility rates, which has been associated with a steady rise in female education levels and with the provision of subsidized modern birth control through organized family planning programs. However, despite this phenomenon and in contrast to similar experiences from the 20th century in developed countries, female laborforce participation has stagnated or even decreased in many developing countries (Coleman and Pencavel, 1993, Schultz, 2009). Lastly, family structure in developing countries, especially

in rural areas, is characterized by the presence of extended families where several generations cohabit in the same household. The combination of these stylized facts might not necessarily mean that there exists an inverse relation between fertility and parental labor supply, especially mothers', as it has been stated for various developed countries.

According to economic theory, although the burden of childcare tends to fall mainly on mothers, an increase in fertility is likely to change the optimal allocation of time within the household, 
and therefore influence the labour supply decision of both mothers and fathers (Becker, 1985). Recently the literature has also focussed on male labour supply, but the few studies examining the impact of fertility on male as well as female labour supply are also limited to developed countries. Therefore, understanding the factors that have an impact on parental labor-force participation in developing countries and how households maximize their labor supply decisions in response to the arrival of a child is quite important not only for theoretical and empirical reasons, but also in terms of public policy implications. For instance, being able to distinguish whether the labor market consequences of childbearing in a developing country are more likely to be severe for poorer or less educated women, could have an important impact on the long-term economic growth of the country.

Not surprisingly, substantial research has been devoted to disentangling the causal mechanism linking childbearing and parental labor supply. Even though the negative relationship between fertility and female labor supply has been well established, interpretation of this relationship is complicated by the endogeneity of the fertility decision that arises when simply using the number of children as the explanatory variable in an OLS regression. Fertility and parental labor-supply are determined jointly and simultaneously within a lifetime household decision making framework. The number of children a couple has is a choice variable which could in principle be influenced by parental labor-force participation. That is, parents who decide to have (more) children are not a random subgroup of the population and, compared to other parents, may have different unobserved economic constraints on the household and preferences that would influence both fertility and labor supply. For instance, women may be more family oriented and, because of this preference, they could accumulate lower human capital and present a lower labor market attachment. By contrast, individuals with high career-based unobservables (such as ambition or talent) may choose to have fewer or no children, and they may be overrepresented in the labor force. Such a potential selection means that a simple cross-sectional correlation between parental labor-force participation and fertility would generally provide biased estimates (Killingsworth and Heckman, 1986). Thus, the identification of this particular causal effect requires a more complex estimation method.

In the literature, two empirical strategies have been mainly used to tackle this endogeneity problem by exploiting an exogenous source of variation in the number of children through Instrumental Variables technique. The first strategy was first introduced by Rosenzweig and 
Wolpin (1980) and uses the natural occurrence of multiple births or twinning at first birth to identify the effect of fertility on labor supply. They find that, although women who have had twins withdraw temporarily from the labor market, their labor-force participation is not affected overall. The second strategy was first proposed by Angrist and Evans (1998) and uses the preference of American parents for balancing the sex composition of their offspring. Since parents of same-sex siblings are more likely to have an additional child, a dummy variable for whether the sex of the second child matches the sex of the first child becomes a good instrument for further childbearing among women with at least two children. They find that fertility has a negative effect on the labor supply of women, but no effect on the labor supply of men.

In the same spirit as Angrist and Evans (1998), the aim of this paper is to investigate the effect of fertility on parental labor-force participation in the context of a developing country in the Balkan region, such as Albania. However, in contrast to American parents which prefer to balance the sex composition of their children, Albanian parents have another fertility preference which is generally known as son preference. ${ }^{1}$ Albania is characterized by a patriarchal family system where parents prefer sons to daughters, especially until they have at least one son. Therefore, the econometric strategy of this paper relies on an Instrumental Variables (IV) Approach, which exploits Albanian parental preference for having sons as an exogenous source of variation in the fertility decision.

The data used in this paper comes from four different surveys conducted in Albania between 2002 and 2012. More specifically, I use the 2002, 2005 and 2012 Albanian Living Standard Measurement Surveys (LSMS) and the 2008-09 Albanian Demographic Health Survey (DHS). The advantage of these surveys is that they contain not only very rich information on individual's demographic characteristics, such as age, years of education for both the head of the household and their spouse, as well as the age and sex of each of their children, but they also have very detailed information on individual's socioeconomic characteristics (i.e. employment, migration, expenditures etc). Another advantage of using the combination of these four dataset is that the sample size increases considerably. For the purpose of this analysis, I construct a repeated-cross section of mothers and fathers with two or more children whose oldest child is younger than 18 years old.

\footnotetext{
${ }^{1}$ There are several previous paper that use parental preference for sons as an instrument for fertility, especially in developing countries. See Ebenstein (2009) for Taiwan, Chun and Oh (2002) for South Korea, Lee (2002) and, Arnold and Zhaoxiang (1986) for China.
} 
This paper makes several contributions to the literature on the causal effect of fertility on parental labor supply. First, this study is, to the best of my knowledge, the first that uses Albanian data to examine the causal link between fertility and parental labor supply in a developing country. It is worth mentioning what makes Albania an interesting setting for this type of analysis. The country has experienced a drastic fertility decline during the last fifty years, which has fallen from almost 7 children per women in 1960 to only 1.65 in 2012 (Gjonça et al, 2008). In addition to low fertility levels, Albania is also characterized by a declining employment rate for both men and women during the last years. According to the Albanian Institute of Statistics (INSTAT), labor-force participation has continuously fallen during the last twenty-five years from 75 percent in 1989 to 62 percent in 2013, being women the most damaged from this decline. Therefore, the setting of a declining fertility rate accompanied by declining employment rates make Albania an interesting case for this analysis. Second, I analyze the impact of fertility on different measures of parent's employment such as work off-farm, work on-farm, self-employed, hours worked per week among others. This is essential in a developing country since labor markets in this context are characterized by higher levels of informality and a considerable share of the employment in rural regions. Third, since there are still few studies that consider the effect of fertility on men's labor-force outcomes, I examine how the mentioned effects differ across gender by including not only women but also men in the analysis. Fourth, I also explore heterogeneity in the relationship between fertility and parental labor supply by examining whether the effect is likely to vary by parent's education, parent's birth cohort and family structure in order to better understand possible mechanisms behind the results.

The results of the paper reveal that on the contrary to previous studies for developed countries, an increase in family size has a positive impact on parental labor-force participation in the context of Albania. More precisely, for the sample of mothers I find that having an additional child (third or higher order) increases on average a mother's likelihood of working off-farm by 5 percentage points and it also increases the working time by around 4.4 hours per week on average. Similarly relevant is the finding that fathers also change positively their labor-market behaviour in response to a change in family size. In particular, having an additional child increases father's likelihood of working off-farm by 6.7 percentage points, and also their likelihood of having a second occupation by 4 percentage points.

While the majority of previous research has emphasized that female labor-force participation 
increases with a decline in fertility rates, this paper argues that this effect might be quite different between developed and developing countries. I propose two plausible mechanisms behind the positive effect of fertility on parental labor supply in the context of a developing country characterized by low fertility and low employment rates. The first one suggests that an increase in fertility faces households to a tighter budget constraint which reduces the standard of living in the household and gives an incentive to parents to increase their labor-force participation in order to respond to an increased demand in the household such as financing basic expenditures on their children. The second one suggests that childcare provided by non-parental adults (i.e grandparents) may act as a substitute for parental childcare in developing countries, thus, allowing them to increase labor supply as a consequence of further childbearing. In line with these hypothesis, the heterogeneity analysis suggests that the labor-market consequences of fertility are more likely to be driven by poorer, less educated, and younger parents. Moreover, mothers living in extended families experience the largest positive effects of fertility on labor supply suggesting that childcare provided by grandparents in extended families might induce mothers to increase their labor supply. On the other hand, the positive effect of fertility on father's labor supply is mostly driven by those living in non-extended families, which suggests that in this type of families parents do not count with childcare provided by grandparents and therefore the mother has to stay in the household while the father probably increases his labor supply.

The remainder of the paper proceeds as follows. Section 2 reviews some relevant previous literature. Section 3 describes the theoretical model. Section 4 provides a brief summary on fertility and labor-force participation for the case of Albania. Section 5 describes the datasets and some descriptive statistics. Section 6 presents the identification strategy and empirical estimation. Section 7 presents the main results of the paper and also discusses plausible mechanisms, and finally Section 8 concludes.

\section{$2 \quad$ Literature Review}

There is an extensive theoretical and empirical literature attempting to explain the effect of fertility on parental labor supply. The majority of these studies focus on female labor supply and they find a negative correlation between the number of children and female labor-force participation. However, more recent studies have also focused on male labor supply, but the few 
studies examining the impact of fertility on male as well as female labour supply are limited to developed countries (Lundberg and Rose, 2002; Millimet, 2000).

Browning (1992) argues in his literature review on this topic that despite a wide number of published papers find a significant and negative relationship between these variables, they do not assess a causal effect due to the endogeneity problems. Therefore, the previous literature on the link between fertility and labor supply can be categorised in several groups according to how the authors have tried to tackle the problem of endogeneity of the fertility decision and whether the studies were done for developed or developing countries.

Some of the studies that focus on the effect of fertility decline on female labor force participation within developed countries are the following: The first group is illustrated by the studies of Gronau (1973), Heckman (1974) and Heckman and Willis (1977) who assumed that fertility is exogenous and established a strong negative correlation between female labor supply and fertility. A second group of studies (Cain and Dooley, 1976; Schultz, 1978; Fleisher and Rhodes, 1979) acknowledged the endogeneity of the fertility decision and tried to deal with the problem by estimating simultaneous equation models. These studies find a much smaller estimate when treating fertility as an endogenous variable. The biggest challenge of this approach is that it is quite difficult to find plausible exclusion restrictions that could identify the underlying structural parameters. A third group of studies incorporates actual fertility as a regressor but adds the lagged dependent variable (i.e. labor supply) to control for unobserved heterogeneity across women. Nakamura and Nakamura (1992) recommended this approach, and it has been used by a number of authors (Even, 1987; Lehrer, 1992). Although adding the lagged dependent variable can help control the unobserved heterogeneity, it still does not address accurately the problem of the endogeneity of the fertility decision.

Finally and most importantly, a fourth group of studies tackles the endogeneity of the fertility variable by exploiting exogenous sources of variation in the number of children. In this literature, two methods based on natural experiments have been mainly used to tackle the endogeneity of fertility: twinning at first birth and parental preference for siblings sex-composition. The pioneering paper using the first method is Rosenzweig and Wolpin (1980). The idea is that some families receive an unanticipated child, and therefore, the treatment and control groups are randomly selected with respect to characteristics that may be related to labor market participation. By comparing labor supply of women who had twins at their first birth with that of women 
who had a single child, they found that an unplanned birth does not impact on female labor participation over the life cycle. A similar identification strategy can be found in Bronars and Grogger (1994), who estimate short and long-run effects of having twins in the first pregnancy for unmarried mothers and find that unplanned births have only short-term effects on unmarried mothers labor supply, while they have no effects among married mothers. A subsequent study by Jacobsen at al, (1998) also studies the impact of unplanned twin motherhood more deeply, and finds that the effects on married female labor supply are negligible in the long-run, while the impact on earnings is more persistent.

The second method in this category uses as an alternative identification strategy the sex composition of the first two children and it was first proposed by Angrist and Evans (1998). In their paper, the authors estimate the effect of a third or higher order child on parental labor supply for the case of U.S, by exploiting the fact that American parents typically prefer mixedsex siblings. Using the sex composition of the first two children as instrumental variables for fertility, they find that in the U.S. fertility reduces female labour supply significantly but that there is no significant change in male labour supply. Chun and Oh (2002) argue that while U.S. households prefer balancing the sex composition of their children, Korean families prefer sons. They use the first child's sex as an instrument for fertility and find that having children reduces the labor force participation of married Korean women by 27.5 percent. $^{2}$

While the evidence for a negative effect of fertility on female labor force participation for developed countries has had much support, there is a scattering of papers in developing countries which show mixed results for the effect of fertility on female labor force participation. Using son-preference as an instrument, Lee (2002) finds no significant effect of fertility on rural female labor supply in China. ${ }^{3}$ Ebenstein (2009) also uses son-preference but he reports a negative effect of fertility on maternal labor force participation in Taiwan. Cruces and Galiani (2007) generalize the results for the U.S. found by Angrist and Evans (1998) to the populations of two Latin American countries (Argentina and Mexico) and also find a negative effect of fertility on female labor force participation. Schultz (2009) uses data from a randomized social experiment

\footnotetext{
${ }^{2}$ Economists have also tried other ways to exploit exogenous variation in family size. Bailey (2006) uses access to the contraceptive pill at state level over time to predict family size. Klerman (1999), Levine et al. (1999) as well as Angrist and Evans (2000) exploit variations in U.S. abortion laws at the state level to identify variations in number of children. All these studies use U.S. data and have found solid evidences for a negative effect of fertility on female labor supply.

${ }^{3}$ Lee (2002) also attempts to use the One-Child Policy, in particular, local family planning rules as instruments, but he suggests that this instrument is potentially endogenous.
} 
in Matlab, Bangladesh and finds a negative effect of family planning programs on female laborforce participation. Another study by Agüero and Marks (2011) analyses the effect of fertility on female labor supply for 26 low- and middle-income countries. By using self-reported infertility as an instrument, they find that there is no effect of fertility on female labor force participation and working intensity. Moreover, based on data from Demographic and Health Surveys covering 59 developing countries and using son-preference, same-sex and twinning as instruments, Porter and King (2009) report that while many women in developing countries are less likely to work when they have more children, some are more likely to work due to many reasons such as greater financial costs of feeding more children. Bloom et al. (2009) combine data from Demographic and Health Surveys with abortion legislation laws in each country, and find mixed results of fertility, similar to Porter and King (2010). There is also a micro study from Priebe (2010), who finds a positive effect of fertility on female labor supply for a developing country. Using Indonesian household annual data from 1993 to 2008, he finds that the effect of fertility is even more positive during the period of the economic and financial crisis (1998-2000) and that it is mostly driven by women which are poorer, less educated and who live in rural areas. His claim behind these results is that the need to finance the cost of children might lead to a considerable share of Indonesian women into the labor force.

\section{$3 \quad$ Theoretical Model}

The model presented in this section is intended to serve as a framework and to motivate the crosssection estimation of the effect of fertility on parental labor supply. Dynamic considerations are ignored for simplicity reasons. In order to explore the factors affecting the relationship between fertility and their parents labor supply in a developing country context, I adapt a unitary household framework that incorporates features of the Becker and Lewis (1973) and Becker and Tomes (1976) quantity/quality model into Blau and Robinss (1988) and Conellys (1992) models of home production.

This model is intended to apply to households in which children requiring continuous care are present and in which the mother and the father, as well as one other potential childcare provider are present (i.e. grandparent, relative etc). In this context, household members utilities are represented by a unique utility function. The household members are assumed to make choices regarding consumption of market goods $(C)$, childcare quality $(Q)$, leisure $(L)$ and the number 
of children in the family $(N)$ in such a way as to maximize their utility $U$ subject to a series of constraints:

$$
\begin{aligned}
& \max \quad U=U\left(C, L_{M}, L_{F}, Q, N\right) \\
& \text { subject to } L_{M}+H_{M}+t_{M}=1 \\
& L_{F}+H_{F}=1 \\
& Q=Q\left(t_{M}, t_{0}, t_{K}\right) \\
& \frac{\partial Q}{\partial t_{M}}=Q_{M}>0, \frac{\partial Q}{\partial t_{K}}=Q_{K}>0, Q_{M M}<0, Q_{K K}<0 \\
& C=E+w_{F} H_{F}+w_{M} H_{M}-\left(p_{K} t_{K}+p_{N}\right) N \\
& t_{M}+t_{K}+t_{0}=1
\end{aligned}
$$

where the subscripts $M$ and $F$ represent mother and father, respectively.

The total time available to the mother is normalized to 1 and can be divided between working hours $\left(H_{M}\right)$, leisure time $\left(L_{M}\right)$ and time spent looking after the children $\left(t_{M}\right)$. Notice that the fathers time is only spent working $\left(H_{F}\right)$ or enjoying leisure time $\left(L_{F}\right)$, in other words, the father does not spend time caring for the children.

The three potential sources of childcare quality are the mother $\left(t_{M}\right)$, the potential informal provider (i.e. grandparents) $\left(t_{0}\right)$ and the formal childcare available in the market $\left(t_{K}\right)$. On the one hand, it is assumed that a formal market childcare quality is available for purchase at hourly price $\left(p_{K}\right)$ per unit of quality. On the other hand, the childcare provided by the mother and the informal provider (i.e. grandparents) is free.

The consumption possibilities of the family are limited by the amount of exogenous income available $(E)$ (i.e. remittances and alike), the amount of income the mother and father earn (their respective wages $\left(w_{F}\right)$ and $\left(w_{M}\right)$ times their respective working hours $\left(H_{F}\right)$ and $\left.\left(H_{M}\right)\right)$ and child costs. Child costs are separated into childcare costs and direct child costs with former ones being modelled as the time devoted to childcare as in Blau and Robins (1988), Conelly (1992) and Kimmel (1998). $\left(p_{K}\right)$ is the hourly price of formal childcare purchased in the market. $\left(p_{N}\right)$ is the price of market inputs required by children and $\left(P_{N} N\right)$ represents direct child costs such as food or non food expenditures (i.e. clothing, school uniforms).

The childs time constraint indicates that the time the child is looked after is equal to the time the mother is looking after her plus the number of hours she is looked after somebody else, 
either in formal childcare or in informal childcare. This constraint rules out the possibility that the family leaves their children on their own.

\subsection{Maximization Problem}

In order to understand how the family chooses between leisure, consumption, childcare purchase and the number of children, I solve the utility maximization problem. The exogenous determinants are the price of childcare; the price of market inputs required by children, the wage rates of the parents and the familys non-labor income.

\subsubsection{Case 1: Nuclear Family}

First, I consider the case where there is no informal childcare provider. The family has to choose between maternal childcare and formal childcare provision in the market. The households maximization problem is the following:

$$
\begin{aligned}
\max _{H_{M} . H_{F}, t_{K}, N} U=U(\underbrace{E+w_{M} H_{M}+w_{F} H_{F}-p_{K} t_{K} N-p_{N} N}_{C}, \underbrace{t_{K}-H_{M}}_{L_{M}}, & \underbrace{1-H_{F}}_{L_{F}}, Q\left(1-t_{K}, t_{K}\right), N)
\end{aligned}
$$

Solving the maximization problem in this case gives one of the following first order conditions:

$$
\left(\frac{\partial U}{\partial Q} \frac{\partial Q}{\partial t_{M}}\right)-\frac{\partial U}{\partial L_{M}}=\left(\frac{\partial U}{\partial Q} \frac{\partial Q}{\partial t_{K}}\right)-p_{K} N \frac{\partial U}{\partial C}
$$

This F.O.C suggests that those households buying childcare in the market will increase the number of hours of this care until the net marginal benefit of an extra hour of formal childcare equals the net marginal benefit of an extra hour of maternal childcare.

The RHS of this equation means that an extra hour of formal childcare increases the households utility by increasing the quality of the child (or childcare). This increase in households utility constitutes the marginal benefit of formal care. The marginal cost of paid care is the decrease in utility induced by the reduction in consumption as a consequence of paying $p_{K}$ for an extra unit of care. The LHS of this equation means that an extra hour of maternal childcare increases the households utility by increasing the quality of the child (or childcare). This is the 
marginal contribution to childcare quality of an extra hour of mothers care. The marginal cost is the decrease in households utility as a consequence of the mothers decrease in pure leisure. Notice that the household does not face the trade-off between maternal childcare and formal childcare when deciding on the fathers optimal amount of working hours.

Dividing (1) by $\partial U / \partial C$, I get an expression for the reservation wage of the mother:

$$
\frac{U_{L_{M}}}{U_{C}}=w_{M}=\frac{U_{Q}}{U_{C}}\left(Q_{M}-Q_{K}\right)+p_{K} N
$$

This interior solution shows that marginal rate of substitution between goods and leisure of the mother equals the wage and the wage in turn equals the net marginal benefit of maternal care, which depends on the difference in maternal and formal childcare quality, on the price of formal childcare which is the money savings form an hour of maternal childcare, as well as on the number of children.

When the wage is lower than net marginal benefit of maternal care $\left(w_{M}<\frac{U_{Q}}{U_{C}}\left(Q_{M}-Q_{K}\right)+\right.$ $\left.p_{K} N\right)$, the mother will not participate in the labor market. While, mothers for whom the wage is higher than the net marginal benefit of maternal care, do participate in the labor market. The higher is the mothers wage, the higher is the likelihood that the household uses formal childcare, which increases the likelihood of the mother to participate in the labor market.

If the quality of maternal child-care is considered higher than that of the formal childcare (i.e. $Q_{M}-Q_{K}>0$ ), the difference between the wage and childcare costs has to compensate for this fact in order to provide a strong enough incentive for mothers to work. In order to increase the incentive for mothers to work, either improvements in formal childcare quality $Q_{K}$ or reduction in the price of formal childcare $p_{K}$ or reduction in the number of children $N$ (all other things being equal) would be appropriate. The interior solution of this simple model of utility maximization of the household suggests that the formal childcare price, the formal childcare quality and the number of children are determinants of the employment decision of mothers with dependent children.

Another first order condition from this maximization problem is the following:

$$
p_{K} t_{K}+p_{N}=\frac{(\partial U / \partial N)}{(\partial U / \partial C)}=\frac{U_{N}}{U_{C}}
$$

The marginal benefit of having an additional child is equal to the marginal cost, which is 
given by the disutility of a decrease in the households consumption equal to total child costs (formal childcare costs and direct child costs). An increase in the number of children has a direct effect on the total cost of childcare by increasing the cost of formal childcare and also the direct child cost. If there are economies of scale in home produced child quality (maternal childcare), then an increase in $N$ will lower the probability of participating in the labor market for mothers.

\subsubsection{Case 2: Extended Family}

A peculiarity of the market for non-maternal childcare is that all households do not face the same prices in the market. Heckman (1974) and Blau and Robins (1988) have each emphasized the potential some families have for lower cost (at least in monetary terms) informal care, most often provided by a relative such as a grandparent. The existence of extended families where grandparents live in the same house as the parents and the children is also a very common feature of developing countries.

In this case, childcare is provided by three sources: the mother $\left(t_{M}\right)$, the informal childcare provider such a relative of grandparent $\left(t_{0}\right)$ and the market formal childcare $\left(t_{K}\right)$. In addition, I assume that maternal childcare and grandparent childcare are perfect substitutes for the children, meaning that both types of childcare provide the same level of quality to the children. I also assume that non-parental childcare (e.x. grandparents's childcare) is provided at a price $p_{0}$, which is lower than the price $p_{K}$ for the market formal childcare. This non-parental childcare price represents the cost related to having grandparents taking care of the children.

The household maximization problem is the following:

$$
\begin{aligned}
\max _{H_{M} . H_{F}, t_{K}, N} U=U(\underbrace{E+w_{M} H_{M}+w_{F} H_{F}-p_{K} t_{K} N-p_{N} N-p_{0} t_{0} N}_{C}, \underbrace{t_{K}+t_{o}-H_{M}}_{L_{M}}, & \underbrace{1-H_{F}}_{L_{F}}, Q\left(1-t_{K}, t_{K}, t_{0}\right), N)
\end{aligned}
$$

I also assume that if informal childcare $\left(t_{0}\right)$ is available at a lower price than the market

childcare, the family will always use. Therefore, the number of hours of informal childcare used by the household is treated as a fixed parameter, which only appears in the childs time constraint and in the childcare production function.

In this case, there is a corner solution to the household utility maximization problem. The 
presence of other potential caretakers in the household such as grandparents or other relatives, lowers the amount parents pay for childcare in the market which in turn increases the labor participation of the mother. Even when an increase in the number of children increases the total cost of childcare, the availability of informal non-maternal childcare in the household allows substituting from maternal childcare to informal childcare, which in turn also allows the mother to participate in the labor market. Therefore, $H_{M}=t_{0}$ and $H_{F}>0$. To sum up, if the grandparent is available to care for the children, childcare is completely informal and mothers participation in the labor market increases.

\section{Background}

\subsection{The Evolution of Total Fertility Rate in Albania}

In the mid-to-late 20th century, when modern contraceptive methods were developed and popularized in other countries, Albania was a Popular Socialist Republic, which promoted an aggressive pro-natalist policy that banned abortion. Modern family planning methods were virtually unknown and, although some were available, access was strictly controlled. The communist government believed that a larger population was necessary in order to protect the country from foreign influences that could exploit its natural resources. When communists took over the government of Albania at the aftermath of the II World War, the country had a population of just over 1.1 million people. In fact they had already found a pro-natalist environment which was reinforced by traditional patriarchal norms. After communism collapsed in 1990, the population had tripled in a period of less than 45 years to 3.3 million. With a total fertility rate of 6 children per woman in 1950, Albania had the highest fertility in Europe, which reached a peak of almost 7 children per woman by 1960 . This rise in fertility during the 1950s and early 1960s mirrors the experience of many European countries during the same period, with the famous baby boom period of the mid-1960s (Gjonça et al, 2008).

Even though during several decades Albania has had one of the highest levels of fertility in Europe, the country has experienced a substantial fertility decline during the last fifty years, which has fallen from almost 7 children per women in 1960 to 1.65 in 2012 . Figure 1 shows the evolution of the total fertility rate in Albania from two different sources - World Development Indicators and INSTAT. The reduction in the fertility rate during the communist regime occurred 
in the absence of modern contraception and abortion, which suggests that other social and economic policies, in particular the ones that improved the social agenda in the country, might have had an indirect effect on fertility in Albania. Most significant of these were policies focused on the improvement of education in the country. For instance, the investment in education, with particular focus on the improvement of female education was unprecedented in Albania. Female illiteracy improved from 92 percent in 1945 to less than 8 percent in 1989, and by 2002 it was less than 5 percent, similar to most developed European countries (Gjonça et al, 2008).

The period after the collapse of the communist regime in 1990 the decline in the total fertility rate has been even more substantial due to the introduction of many new laws and social policies which have aimed to regulate the transition to a more market-oriented and modern society. One of the first changes in legislation that the Albanian Government introduced in 1995 has been the legalization of abortion. Also, family planning methods have become widely available, even though the level of information and education for its use still remain low. In addition, the political openness in the early 1990s has permitted people to move freely and also to emigrate. As a consequence, an enormous emigration mass took place in a very short period of time which was concentrated in the reproductive age groups. While the move towards market economy has been associated with the emancipation of the society in general and women in particular, it has also generated negative consequences in terms of employment. The collapse of industry brought back a large unemployment, especially for women (UNFPA, 2012; Gjonça et al, 2008).

During the transition period studied in this paper (2002 - 2012), it is clear that Albania has a new setting with regards to fertility compared to the communist period. The existence of means of birth control which were not present before 1990, the high female unemployment rates, the economic crisis and the continuing emigration are several factors that might have contributed to the declining fertility rate during this decade.

\subsection{Labor-Force Participation in Albania}

During the communist regime, the labour market in Albania was characterized by a state controlled individual decision-making and a high degree of centralization. In this system, there were social and economic policies that promoted continuously the equality between women and men in different social spheres, including the labor market. For instance, the constitution of the Peoples Socialist Republic of Albania (Article 41) stated "The woman enjoys equal rights with a man in 
the work place, payment, holidays, social security, education and in all social-political activities as well as in the family" (Kuvendi Popullor, 1976). Since the communist regime was interested in full female employment, the government provided support to the families through social and economic policies including child care benefits and maternity leave schemes, complemented by a state-sponsored system of day-care nursing and kindergartens across the whole country. In addition, the prices for a number of essential products for children were subsidized by the state. As a result, women were freed from childcare responsibilities and were thus able to work. In 1989, female labor-force participation had reached 72.8 percent, an increase of more than 50 percent compared to 1960 (35.9 percent) and by that time there were only slight differences in labor-force participation between men (77.2 percent) and women (72.8 percent) (Gjonça et al, 2008; INSTAT, 2004a).

After the collapse of the communist regime in 1990, Albania went through many radical demographic, economic and political changes. The labor market was not an exception to this. In the early 1990s, the labor market was liberalized and a mass of state-owned enterprises were privatized. This period was followed by a high degree of unemployment as a result of the shutting down of major industries. Labor force participation fell by 15 percentage points for the period 1989-2001, and since 2000 less than two thirds of the working age population is actively participating in the labor market. The decline in labor supply was more pronounced for women. The workforce lost more than a quarter of women, but only 5 percent of men. By 2001, gender equality had disappeared, as only half of the adult women were active in the labor market (49.7 percent) and the proportion of inactive women had doubled. Labour force participation among men remained roughly the same but its composition changed as the share of the employed fell (61 percent relative to 71 percent in 1989) and the share of unemployed rose (14 percent relative to 6 percent). Also, the size of the male labour force was reduced in absolute numbers as a result of emigration (INSTAT, 2004a).

During the transitional period in Albania, which is not over yet, women in particular have faced a substantial withdrawal from the labor market due to several reasons. First, state enterprises, where women made up the greatest percentage of the workforce before 1990 collapsed due to their inefficiency and so did social protection associated with these jobs (Tarifa, 1996). Second, the state stopped providing child care or long paid maternity leaves and at the same time many day-care nurseries and kindergartens were closed. For instance, compared to 1990, the 
number of kindergartens had fallen by 60 percent in urban areas and by 49 percent in rural areas in 2004 (IMF, 2006). ${ }^{4}$ Third, during this period the country also witnessed a massive male emigration, which has left the wives at home taking care of the children, engaging in housework or informal market and thereby decreasing their working hours out of the house. Also, the internal migration to urban areas has damaged the labor supply of women since they face more problems entering the urban labor market in the current economic environment. Consequently, women's schedules have required more accommodation giving rise to long-term structural discrimination in the labor market and high female unemployment rates.

Labor force participation has still remained low in Albania during the last decade, especially for young people and women. Statistics from INSTAT (2014) show that the labor-force participation rate for women between 15-64 years old is 50.1 percent whereas for men is 70.2 percent. This difference of 20.1 percentage points in favour of men clearly reflects the unequal participation of women and men in the labor market. Employed women are still finding it more difficult to balance career and family as the availability of state-financed social services is quite low and the number of pre-school facilities has not recovered to the levels previous to the collapse of the communist regime (See Figure 3). The lack of adequate public day-care nurseries and kindergartens as well as the the expensive rates of private childcare institutions have forced women to abandon employment in order to take care of the children. As a result, two decades after the fall of the communist regime, one may observe that the mutual support between family members has assumed a great role in attenuating the shock of poverty inherited from the communist regime, and that informal channels of support function better than the state social provisions and assistance (Danaj, 2014).

Therefore, a distinguishing feature of this study is that it is quite interesting to analyze the effect of fertility on parental labor force participation in a developing country characterized by a combination of low levels of employment and also low fertility rate. Figure 2 presents these trends since 1990 until 2012 for the case of Albania, where we can clearly observe a decrease in both variables. The timing of these events suggests that there might exist a causal relationship between them. However, the combination of these two stylized facts (low labor-force participation and low fertility) does not necessarily mean that there exists an inverse relation between fertility and labor supply, as it has been stated for various developed countries.

\footnotetext{
${ }^{4}$ See Figure 3 for more detail on the situation of pre-school in Albania during the period analyzed in this study.
} 


\section{The Data}

The data used in this paper come from surveys conducted in Albania in four different moments in time: the 2002 Living Standard Measurement Survey (LSMS), the 2005 Living Standard Measurement Survey (LSMS), the 2008-09 Demographic Health Survey (DHS) and the 2012 Living Standard Measurement Survey (LSMS). The LSMS surveys were undertaken by the Albanian National Institute of Statistics (INSTAT) with the technical assistance of the World Bank. The 2008-09 DHS was conducted by the INSTAT but also by the Institute of Public Health (IPH). These surveys correspond to different wave rounds, but it is important to note that they do not form a panel database. They are nationally representative surveys for the whole country, as well as at regional and at the urban/rural level. Each survey contains a wide range of information on individuals demographic and socioeconomic characteristics (i.e. fertility, health, employment, migration and education among many others). In each one of these databases, the country is stratified into four regions (strata), Tirana, Coastal, Central and Mountain. All the surveyed individuals belong to the 36 districts in the country, with all regions nearly equally represented.

These surveys interviewed both women and men with respect to their fertility decisions, thereby permitting the unique opportunity to incorporate information in my study regarding the fertility history of each household. In other words, each one of these surveys contains detailed information which helps identify children by birth of order and match them with their biological mother and father. For instance, in the 2008-09 DHS survey, all the children ever born are already matched to each one of their corresponding mother and father, which makes the DHS a perfect database for studying the fertility history of the parents. In contrast, in the LSMS surveys, the fertility history information is not as clearly identified as in the DHS, which means that the children are not already linked to their corresponding parents. However, the advantage of the LSMS surveys is that they provide a direct mother and father identifier code, which is used to link the children to their corresponding parents. In addition, the Albanian LSMSs databases are a special case in terms of fertility compared to other LSMS surveys because they contain very detailed information on the family structure of each one of the households, including information about the children no longer living in the household, which makes possible the construction of the entire fertility history of each parent in the databases. ${ }^{5}$ 
Following similar studies in the literature, I limit the analysis to mothers aged between 20 and 49 years old with at least two children whose oldest child was at most 18 years old at the time of the surveys. Firstly, women who are younger than 20 years old are excluded from the analysis because none of them have two children. Since the instrumental variable used in this study is based on a comparison of the sex of the parent's previous children, it is necessary to include only individuals with two or more children. Secondly, mothers with children older than 18 years old at the time of the survey are also excluded from the sample. This restriction ensures that the first child has not yet moved from home at the time of the survey. ${ }^{6}$ Additionally, mothers with a child below the age of 1 are also excluded from the analysis in order to avoid potential bias due to lower labor market activity of mothers during the initial months following childbirth.

Taking into account these restrictions, with these four surveys I construct two repeated-cross section subsamples. The first includes mothers with two or more children whose oldest child is younger than 18 years old. The second includes fathers (husbands of the married mothers) with two or more children whose oldest child is younger than 18 years old. I do not carry out a separate analysis on the subsample of married women because in my final sample the married women represent 98 percent of the total (see Table 2), which makes no significant difference with respect to the whole sample. Thus, the final samples are made up of 7,480 observations of mothers and 5,496 observations of fathers with at least two children under the age of $18 .^{7}$

\subsection{Descriptive Statistics}

Descriptive statistics for mother's fertility in Albania are given in Table 1. As the independent variable of primary interest for this analysis is fertility, the variable number of children ever born

\footnotetext{
${ }^{5}$ The 2002 LSMS contains a specific module on fertility, where it is possible to identify the maternity history of every woman in the database. This type of module is not included in the 2005 and 2012 LSMS surveys, but for these cases the Migration module and Sons and Daughters Living Away module are used to construct the fertility history.

${ }^{6}$ In Albania, it is increasingly likely for a a child over 18 years old to have moved to a different household. For instance, using the LSMS surveys, which provide information on the sons and daughters who have left the household, I find that the average age at which a child in Albania left his home is 23.66 during the period studied. Moreover, the age at which a child left the household is quite different between males and females. For example, the average age at which a girl left home is 21.92 years old, while for boys it is 25.41 . These descriptive statistics indicate that Albanian girls leave their homes quite earlier compared to boys and this is generally due to marriage.

${ }^{7}$ It is important to note that the difference in observations between the married mothers $(7,480)$ and the married fathers $(5,496)$ is due to the fact that the number of observations as provided in the official 2008-09 Albanian DHS dataset is not similar between women and men. In other words, there are more observations of women than men. A detailed description of the LSMS surveys and the DHS survey for Albania and on the construction of the subsamples and some key variables is provided in appendix A. See Table A-1 in the Appendix for more information.
} 
per mother is used as a measure for fertility. ${ }^{8}$ Using the sex of the oldest two children, I define the siblings sex composition pairs as same sex if they have the same gender and mixed sex if otherwise. The former is also decomposed to define sibling pairs of two girls and two boys.

Table 1 indicates that the average number of children ever born for Albanian mothers with at least two children is 2,60. Some families have as many as 9 children. Among all mothers with two children, about 41 percent considered having a third child, an event indicated by the variable More than 2 children. Both the number of children and the proportion of mothers with three or more children are quite similar to other studies in the literature (e.g. Angrist and Evans, 1998). Moreover, just 50 percent of the households with at least two children had either a girl or a boy as a firstborn and also just 50 percent of all two child households had children of the same sex. However, the occurrence of two boys in a row is slightly higher ( 25 percent) than the occurrence of two girls (24 percent).

Demographic and labor-force participation descriptive statistics for mothers and fathers are given in Tables 2 and 3, respectively. These tables include variables such as parent's age, age at first birth, years of education, household size, residential region and indicators for religion among others. The labor-force participation variables are based on questions concerning the employment status of the parent during the last 7 days and 30 days previous to the moment of the surveys. The four surveys (LSMS and DHS) contain labor supply indicator variables which measure whether the parents worked for somebody other than a household member (worked off-farm), whether they worked on a farm owned by a household member (worked on-farm) and whether the parents worked on own account (self-employed). It is important to notice that these working activities are not exclusive, which means that each parent might be doing more than one. Thus, I define another indicator variable that combines these three variables and takes the value of 1 if the parents performed at least one of these working activities during the last 7 days (worked in last 7 days) and 0 otherwise.

Just the LSMS surveys also contain other labor supply variables that measure whether the parents have a second occupation, their usual number of hours worked per week and also their amount of labor income per month in old leks. ${ }^{9}$ The latter two variables are set to zero for those

\footnotetext{
${ }^{8}$ This measure of fertility number of children ever born also includes the deceased children. Results using indicator variables for More than two children give similar conclusions. These results are available from the author upon request.

${ }^{9}$ The 2002 and 2005 LSMS surveys also contain information on the number of weeks worked per year, but unfortunately this variable is not availabe for the rest of the surveys and for this reason it is not used as an
} 
parents who reported not working during the last 7 days.

The descriptive statistics in Tables 2 and 3 indicate that the mean age is 35 for the sample of mothers and almost 40 for the fathers (husbands or partners of mothers). On average, women become mothers at the early age of 23 compared to 28 for men. Parents in Albania complete a similar number of years of education, being 10 years for the mothers and 11 for the fathers. Half of the households in the sample live in urban areas and around 38 percent of the them live in an extended family.

About 44.5 percent of the mothers with at least two children were working during the last 7 days previous to the surveys, whereas this number rises up to 78.7 percent for the sample of fathers. This difference of 34.2 percentage points in favour of labor-force participation of men reflects their much more active involvement in the labor market of Albania. In addition, fathers are much more likely of having a second occupation (5.8 percent) compared to mothers (1.4 percent). From the sample of mothers with at least two children, 16.3 percent were working off-farm, 21.7 percent were working on-farm and only 6.6 percent were self-employed. While, for the husbands or partners of mothers, 39.3 percent were working off-farm, 23.6 percent were working on-farm and 19.7 percent were working on own account. This summary statistics indicate that men in Albania dominate in the non-agricultural sector, while women make up a higher proportion of employed persons in the agricultural sector.

Overall (i.e., including zeros), the average number of hours worked per week is 16.6 among the mothers, but it is 40 hours among those that effectively work. On the other hand, fathers in the sample worked 34.2 hours per week (i.e., including zeros) and this number rises up to 44.8 for those that worked a positive number of hours. Lastly, the average monthly labor income for mothers with at least two children is 50,166 old leks (221,591 without zeros), whereas fathers earn on average 191,841 old leks (331,172 without zeros), which is quite more compared to mothers. ${ }^{10}$ Once again, it is important to notice the gender inequality in terms of labor-force participation and earnings in Albania during the period analysed in this study.

additional dependent variable in this study

${ }^{10}$ Monthly labor income is in real terms with base year 2007 using the national CPI provided by the Albanian National Institute of Statistics (INSTAT). 


\section{Empirical Strategy}

When exploring the causal relationship between fertility and parental labor-force participation, the most difficult task for the researcher is to give an appropriate consideration to the endogeneity problem. In this context, the endogeneity of fertility arises mainly due to reverse causality and omitted variables. Firstly, it is likely to think that parents who participate less in the labor market tend to have more children than those who are more active. That is, fertility decisions are likely made taking into account own employment status and also spousal employment status or other factors of family structure. Secondly, there might be omitted variables such as individual heterogeneity in preferences that affect both parental labor supply and fertility behavior. Failing to account for such endogeneity means that an estimated relationship between fertility and parental labor supply will not have a causal interpretation. Hence, estimating the causal effect of having an additional child on parents labor supply straightforward by including the number of children as an explanatory variable in an OLS equation would produce biased and inconsistent estimates. However, an instrumental variable technique addresses this endogeneity problem and offers a way to achieve consistent estimates of the effect of fertility on parental labor-force participation. But finding a good instrumental variable that is correlated with fertility and simultaneously exogenous to the parental labor supply decision is a very difficult task.

As stated in the previous literature, two empirical strategies based in the instrumental variables (IV) technique have been mainly used to tackle the endogeneity of the fertility decision: twinning at first birth (Rosenzweig and Wolpin, 1980) and parental preference for sibling's sexcomposition (Angrist and Evans, 1998), both of which involve a plausibly random biological

phenomenon that induces a sub-population of families to have more children than they otherwise would. In this paper, I adopt the latter empirical strategy which uses sibling sex-composition as an instrument for fertility in order to estimate the causal effect of fertility on parental labor-force participation in a developing country in the Balkan region, such as Albania.

For this empirical strategy to identify the parameter of interest, the instrument sibling sexcomposition must satisfy two basic conditions. The first condition, also known as the relevance condition, requires that sibling's sex-composition must be strongly correlated with the endogenous variable -fertility-. The second condition, also called exclusion restriction, requires that the sibling's sex-composition must have no correlation with factors directly affecting parental labor-force participation other than through its impact on fertility. If either of these two con- 
ditions is not met, then the IV estimation can lead to large standard errors, asymptotic bias and inconsistent estimates (Wooldridge, 2003; Bound at al, 1995). The next section describes the instrument sibling's sex-composition in the context of Albania. It also discusses whether it satisfies these two conditions, and whether it is, thus, a valid instrumental variable for further childbearing among parents in Albania.

\subsection{Identification of the casual effect using Instrumental Variables}

\subsubsection{Son Preference in Albania}

Several demographic analyses have confirmed that son preference is a distinctive feature of Albania's population (UNFPA, 2012; Gjonça et al, 2008). It is well documented that if the first child of an Albanian couple is a daughter, they will try to have at least one more child (Zickel and Iwaskiw, 1994). The country is characterized by a patriarchal family system organized

along male patrilines. Son preference in Albania is partially driven by the desire and need to perpetuate the family name, but is also reinforced by a collection of customs that make a son desirable economically. For instance, Albanian sons are considered more economically productive than daughters because in general they obtain higher wages.

Old-age support from mature sons is another influential factor in parental decisions to have sons in Albania. They are still more preferred than daughters because they provide a greater source of protection and expected support for the parents at old age, a need reinforced by the uncertainties of the economic and social environment since the exit from the communism in the early 1990s. Moreover, Albanian tradition and culture dictates that sons should provide financial support and protection for parents, and for this reason the elderly commonly reside with their youngest adult son. On the contrary, the obligation on daughters is weaker, in part because they are considered as transient members of their native family and also because they are thought to be responsible for their husband's parents. According to custom, and in the absence of social insurance, parents are better served by ensuring the presence of a son and daughter-in law than the presence of a daughter and a son-in-law.

Given this patriarchal Albanian context, in order to address the potential endogeneity in the fertility decision, I exploit Albanian parental preference for having sons as an exogenous source of variation. The idea behind this identification strategy is that, parents whose first two children are girls should have higher fertility in pursue of the male child compared to parents with other 
sibling's sex-compositions. Similarly, parents whose two first children are boys should be less likely of having an additional child because they have already reached the goal of having at least one son. Therefore, a set of dummy variables indicating whether a mother's first two children are two girls, two boys or whether they have the same sex can be used as instrumental variables for higher order fertility. Naturally, a necessary restriction of the sample is to include only mothers with at least two children. This identification strategy is akin to Angrist and Evans (1998), but since parental sex preferences in the Albanian context are different from the ones in the United States, I argue that the instrumental variable (two girls) should be more powerful for influencing progression to higher parity compared to the instrument same sex used by the authors. However, as the phenomenon of parental preference for balancing the sex-composition of the children has been widely documented in previous studies, I also use this alternative source of exogenous variation as a robustness check.

\subsubsection{The Relevance Condition}

How much does the sex-composition of previous offspring influence progression to higher parity in Albania? In order for the instrument to be valid, the relevance condition requires that sibling's sex-composition must be strongly correlated with fertility. Table 4 reports raw estimates of the impact of child sex and the sibling's sex-composition on fertility. The first panel (Panel A) presents sex preference in households with at least one child who had a second child, conditional on the sex of the first child. The figures show that around 50,6 percent of mothers have a boy as a firstborn, while approximately 49,3 percent correspond to mothers whose first child is a girl. The next three columns show the fraction of mothers with either a boy or a girl as a firstborn that had a second birth. The first column corresponds to the impact of the sex of the firstborn on fertility for the entire sample of mothers with at least one child, while the other two columns show the results decomposed by urban-rural areas. It can be observed that mothers with a female firstborn child are more likely to have a second birth than those with a male firstborn child. The difference is statistically significant at the 1 percent level and it is even bigger in rural areas. This estimate suggests that subsequent fertility is a function of the sex of this first child and it is the first evidence of son preference in Albania.

The second panel of Table 4 documents parental sex-mix preference in households with at least two children who had a third child, conditional on the sex of the first two children. The 
first four rows in this panel show the fraction of the sample represented by mothers whose two first children are: first one boy and then one girl, first one girl and then one boy, two girls and two boys. The next two rows report statistics for mothers with two children of the same sex and for those with mixed sex. The final row reports the difference between the same sex and the mixed sex group averages. Estimates in column (1) suggest that Albanian mothers with two children of the same sex are much more likely to have a third child than those with one boy and one girl. More precisely, only 34,7 percent of mothers with a mixed sex siblings composition have a third child compared to 48.7 percent of mothers with a same sex siblings composition. This difference is statistically significant at the 1 percent level and rises up to 14 percentage points, which is much bigger than the difference found in previous papers.

Furthermore, the correlation between sibling's sex-composition and the probability of additional childbearing is even stronger for mothers whose two first children are girls, reaching a statistically significant difference of 26 percentage points compared to mothers with a different sex-composition. For instance, estimates in column (1) indicate that around 61,4 percent of Albanian mothers with two girls have a third child compared to only 36,4 percent for those with two boys or even less for those with a mixed sex combination. Columns (2) and (3) indicate that fertility rate is higher in rural areas compared to urban areas and that parental preferences for sibling's sex-composition differ slightly by rural-urban decomposition, but the same pattern remains in both areas. These correlations suggest that Albanian parents have a clear preference for sons, which is more pronounced in rural areas compared to urban areas.

Overall, even though the total fertility rate has declined during the period studied, fertility patterns following two girls demonstrate the persistence of parental preference for sons. For instance, in Figure 4 mothers who give birth to a girl followed by another girl have a much higher fertility than those who give birth to mixed sex siblings or two boys in a row in each one of the four databases used in this study. On the contrary, mothers who give birth to two boys in a row are less likely to have an additional child compared to those with an otherwise sex-mix. This result also indicates that, for Albanian parents, balancing the sex-composition of their children is not as preferred as having sons because if they did, they should want to have a girl if they already had two boys and this does not seem to be happening. ${ }^{11}$

\footnotetext{
${ }^{11}$ It is important to notice that the relationship between sibling's sex composition and further childbearing is confirmed in each one of the databases used in this study (LSMS and DHS surveys). This is important because, unlike the 2005 and 2012 LSMS surveys where information about fertility is partly based on my own household
} 


\subsubsection{The Exclusion Restriction}

In addition to the relevance condition, the exclusion restriction requires that the sibling sexcomposition has no correlation with other factors directly affecting labor-force participation other than through its impact on fertility. This condition means that it is of primary interest that the instrument has an as close a resemblance as possible to a random assignment. Basically, sibling sex-composition is supposed to be unrelated to any unobserved factors that might affect parental labor supply because in essence it is virtually randomly assigned by a biological natural phenomenon.

Even though the sex of a child is plausibly randomly assigned, there exist several concerns that might put this statement into doubt and threaten the identification strategy of this analysis. One important concern is the prevalence of the sex-selective abortions in Albania. In view of a manifest preference for sons, the sex-ratio has recorded a significant rise since the mid-1990s due to the legalisation of abortion and also the modernization of the available reproductive equipment, reaching 114 male births per 100 female births around 2005 (UNFPA, 2012). Hence, if the parents who prefer to have sons or the mothers who want to return to work are willing to engage in sex selection, the instrument will not be randomly assigned. Despite the fact that Albania has a high sex-ratio, the evidence from the sample of mothers and fathers used in this paper suggests that the sex-ratio at first and second order births is very close to the natural rate, which makes this issue a minor concern. (see Table 1 and 4). ${ }^{12}$

Another simple way to check whether the instrument is as good as random is to examine whether parents differ in demographic characteristics by the sex-compositions of their two first children. (Agüero and Marks, 2008; Angrist and Evans, 1998). The idea is that if there is no correlation between the instrument and other variables affecting parental labor supply, then there should be no systematic differences in demographic characteristics between parents who

matching between the children and their corresponding parents, the 2002 LSMS and 2008-09 DHS contain detailed fertility histories for each parent, including information on the dates of birth and sex of each child among others. This serves as a cross check for the relevance condition of the instrument. Tables A-2 and A-3 in the Appendix report estimates of the impact of child sex and sibling's sex-composition on fertility for each one of the four surveys.

${ }^{12}$ Several methods to discriminate among unborn girls co-exist today in the world. The most recent methods are based on pre-conception selection and require access to the elaborate equipment necessary to perform sperm sorting, pre-implantation genetic diagnosis (PGD) or in-vitro fertilization (IVF). Cost and accessibility factors, however, restrict these technologies to developed countries and to the most affluent populations. It is very unlikely for Albanian families to incur in such practices due to their high cost but also because their availability is almost non-existent in Albania. On the contrary, sex selective abortions offer a far easier and more accessible route to avoid female births (UNFA, 2012). 
have same-sex and mixed-sex sibling compositions, and similarly between those who have two girls and another sibling composition or two boys and otherwise. Examples of such variables are age, age at first birth, years of education, rural area and religion.

Table 5 reports the difference in means in demographic characteristics between parents (mothers and fathers) with different sibling's sex-composition (same-sex, two girls and two boys). Columns (1) and (4) indicate that mothers (fathers) with children of the same sex and mothers (fathers) with children of mixed-sex, have similar demographic characteristics before the treatment, that is, the arrival of the third child. The rest of the estimates in Table 5 show that in general there are no statistically significant differences in demographic characteristics between parents with two boys and those with another sibling composition, and also between those with two girls and otherwise, except for the variable age. Parents with two girls and just the fathers with two boys seem to be slightly older than those with another sibling composition. The magnitude of these differences represents only 1 percent of the sample means of age for mothers and fathers, which is quite small. However, the variable age is used as a control in all the specifications of the paper in order to avoid any concerns.

Another possible threat to the validity of the exclusion restriction in this identification strategy is put forward by Rosenzweig and Wolpin (2000). They argue that having mixed sex siblings may violate the exclusion restriction by directly affecting both the marginal utility of leisure and child rearing costs and, thus, labor-force participation. For example, if spending on various child-related goods is different for parents who have a son versus those who have a daughter, the analysis will be contaminated by the direct impact of a child's sex on childcare costs. Using Indian data, they find that expenses for clothing of the third child are significantly lower if the older siblings are of same sex. They attribute this effect to hand-me-down savings, which are more likely to arise when there are children of the same sex in the household for items such as clothing or footwear. Since these items represent a sizeable fraction of the Indian households expenditures (11 percent of the household income), they note that the sex composition of children plausibly alters female labor supply through mechanisms other than through fertility change alone.

Table 6 reports data on budget shares of child-related goods and mean household expenditure differences by sibling sex composition for Albania. ${ }^{13}$ The statistics show that Albanian

\footnotetext{
${ }^{13}$ The data used for analyzing the expenditure patterns in Albania come only from the 2002, 2005 and 2012
} 
households devote about 55 percent of their budget to food, 5.4 percent to health, 4.6 percent to clothing and 2.5 percent to children's education. In the clothing category, children's clothing expenditure represents only 2 percent of the entire budget. This estimate seems to be too small compared to the Indian case in order to account for a meaningful reduced form relationship between the sibling sex composition and parental labor supply. ${ }^{14}$ In addition, the evidence in Table 6 shows that expenditure patterns of households in Albania are not significantly affected by the sex composition of children. For instance, in one of the cases where the difference between budget shares is statistically significant, the sign contradicts the presence of economies of scale, since households whose first two children are girls spend a higher share of their budget on clothing. Also, even though Albanian parents with same-sex siblings seem to spend a lower proportion of their budget in children's education, the magnitude of this difference is too small to make a real impact, given the fact that children's education represents only 2.5 percent of the entire household budget. These statistics suggest that there is not a clear expenditure pattern of the Albanian parents by sibling sex composition. Therefore, the instrument seems not to be related to any indirect income effects that might question its exogeneity. ${ }^{15}$

Lastly, it can be argued that another possible threat to the exogeneity of the instrument is the fact that having two girls as the oldest children can make it easier for the parents to increase their labor supply as the older girls can do household chores and take care of the younger siblings. Therefore, having two girls might have a direct effect on parental labor supply. However, it is worth pointing out that this may be a bigger concern for the results of the mothers, but is unlikely to explain results for the fathers. In order to deal with this issue, in the estimation strategy I control for the gender of the first child. ${ }^{16}$

Albanian LSMS surveys. Unfortunately, there are no available expenditure data on the 2008 DHS survey. The LSMS surveys contain very detailed information on household food and non-food expenditures. These databases have also the advantage of making possible the separation of child clothing and education expenditures from adults expenditures.

${ }^{14}$ Cruces and Galiani (2007) make a similar argument for the cases of Argentina and Mexico. They indicate that sex composition in unlikely to have a noticeable effect on clothing and footwear expenditure for these Latin American countries due to the fact that only around 4.8 percent of the budget was used for clothing and footwear in the year 2000 in Mexico, while 6.7 percent for the case of Argentinean households (for all members).

${ }^{15}$ Huber and Mellace (2011) developed a test to assess the validity of an instrumental variable in just-identified models and applied it to the AEs database finding evidence for the validity of same-sex.

${ }^{16}$ In order to further address this concern I also check the robustness of the main results for the mothers when the sample is limited to families were the oldest child is less than 13. As in Albania the average age for finishing primary school is 13, it is reasonable to argue that girls would not be asked to take care of siblings if they are younger than 13 years old. In the Appendix, estimates in Table A-5 indicate that the main results remain unchanged after limiting the sample of mothers to those whose oldest child is younger than 13 years old. 


\subsection{The Econometric Framework}

\subsubsection{Potential Drawbacks of OLS}

This section discusses the ordinary least square (OLS) and the instrumental variables (IV) techniques and presents the regression models relating parental labor-force participation and fertility. To begin with, I examine the effect of fertility on parental labor-force participation by using OLS through the following linear model:

$$
L F P_{i j s}=\beta_{0}+\beta_{1} F_{i j s}+\varepsilon_{i j s}
$$

Here, $L F P_{i j s}$ is a measure of labor-force participation of the parent $i$ residing in district $j$ and observed in survey year $s$ (i.e. dummy indicator for worked in last 7 days or hours worked per week among others); $F_{i j s}$ is the endogenous fertility variable measured through the number of children ever born per parent $i$; and $\varepsilon_{i j s}$ is the error term associated with unobserved heterogeneity for the parent. The parameter of interest, $\beta_{1}^{O L S}$, represents the mean effect of having an additional child (third or higher order) on parental labor-force participation. It is of most importance to notice that when we estimate the model in equation 7 by ordinary least squares (OLS), the estimator $\beta_{1}^{O L S}$ is likely to be inconsistent due to reverse causality and omitted variables. First, labor-force participation outcomes and fertility are jointly determined. Second, omitted variables such as parental cognitive ability and preferences are plausibly correlated with both labor supply and number of children (fertility). In particular, the magnitude of $\beta_{1}^{O L S}$ is likely to be biased upwards due to unobserved ambition or ability which positively influences the outcome variable but is probably negatively correlated with having an additional child.

\subsubsection{Instrumental Variables Estimation: LATE}

In order to disentangle the causal mechanism linking fertility and parental labor supply, I use sibling sex-composition as an instrument that induces plausibly exogenous variation in $F_{i j s}$ (the number of children ever born). As stated previously, this identification strategy is based on the fact that Albanian parental preference for sons (instrument has an impact on the number of children, but is supposed to be unrelated to any unobserved factors that might affect parental labor supply.

When using an Instrumental Variables (IV) technique, which allows for heterogeneity of the 
treatment effect (fertility) on the outcome variable (parental labor-force participation) and selection on unobservables, the parameter of interest $\beta_{1}^{I V}$ is no longer able to identify consistently the average treatment effect or the average treatment effect on the treated (Imbens and Wooldridge, 2009). However, under reasonably general assumptions (independence and monotonicity), the estimate $\beta_{1}^{I V}$ captures the local average treatment effect (LATE), first discussed by Imbens and Angrist (1994). The $\beta_{1}^{I V}$ estimate can, then, be interpreted as the average effect of $F_{i j s}$ on $L F P_{i j s}$ for those parents whose fertility has been affected by the sex-mix of their previous children. Following the terminology in Angrist et al (1996), in order to better understand for which subgroup of parents with two children the average treatment effect can be consistently estimated, it is useful to classify them into the following 3 sub-populations: those who will have a third child even following a son (always takers), those who will never have a third child even following two daughters (never takers), and those who will have a third child following two daughters but would otherwise stop (compliers).

Hence, $\beta_{1}^{I V}$ can consistently estimate the average effect for individuals who have one more child because their first two children are girls (i.e. compliers) provided that the instrument satisfies monotonicity. Basically, what is needed to be assumed is that there are no defiers, those that change their behaviour in the opposite direction due to the instrument. In other words, monotonicity requires that having never had a son only makes one more likely to have a third child, a reasonable assumption given the pervasive son preference in Albania. The IV approach fails to identify the effect among two sub-populations: the always takers, who generally have lower costs to childbearing than compliers, and the never takers, who will generally have higher costs to childbearing than compliers.

Therefore, the second-stage regression model that links the endogenous fertility measure $\hat{F}_{i j s}$ with labor supply variables for the parents is the following:

$$
L F P_{i j s}=\beta_{0}+\beta_{1} \hat{F}_{i j s}+\beta_{2} b_{1}+\beta_{3} b_{2}+\beta X_{i j s}^{\prime}+\mu_{s}+\lambda_{j}+\varepsilon_{i j s}
$$

where $L F P_{i j s}$ measures labor-force participation of the parent $i$ residing in district $j$ and observed in survey year $s ; \hat{F}_{i j s}$ is the endogenous fertility variable measured through the number of children ever born per parent $i ; X_{i j s}^{\prime}$ is a set of control variables that are plausibly exogenous to fertility, such as parent's age, parent's age squared, parent's age at first birth and parent's years of education; $b_{1}$ and $b_{2}$ are indicators for the sex of the first and the second male child 
of parent $i$, respectively, and $\varepsilon_{i j s}$ is the error term associated with unobserved heterogeneity for the parent. The variables $b_{1}$ and $b_{2}$ are included to control for potential additive effects of child gender, which might affect labor supply for reasons other than fertility (number of children ever born). For example, as mentioned in Angrist and Evans (1998), this effect could arise if parents behave differently towards boys and girls. For this reason, the sex of the first-born and the second child, $b_{1}$ and $b_{2}$, are included in the equation to minimize any omitted variable bias caused by additive effects of child sex. I also control for the gender of the first child in order to address potential concerns about the exclusion restriction related to the fact the having to two girls might have a direct affect on parental labor supply.

Initially, the first-stage regressions for the just-identified models that link the potentially endogenous fertility variable to only one instrument are the following:

$$
\begin{array}{r}
\hat{F}_{i j s}=\alpha_{0}+\alpha_{1}(\text { samesex })_{i j s}+\alpha_{2} b_{1}+\alpha_{3} b_{2}+\alpha X_{i j s}^{\prime}+\mu_{s}+\lambda_{j}+v_{i j s} \\
\hat{F}_{i j s}=\alpha_{0}+\alpha_{1}(\text { twogirls })_{i j s}+\alpha_{2} b_{1}+\alpha X_{i j s}^{\prime}+\mu_{s}+\lambda_{j}+\eta_{i j s} \\
\hat{F}_{i j s}=\alpha_{0}+\alpha_{1}(\text { towboys })_{i j s}+\alpha_{2} b_{1}+\alpha X_{i j s}^{\prime}+\mu_{s}+\lambda_{j}+\xi_{i j s}
\end{array}
$$

where the sibling sex-composition instrument is measured by three dummy variables, same sex, two girls and two boys, indicating whether the sex of the first child is the same as that of the second child. Given the Albanian parental preference for sons, $F_{i j s}$ is expected to be positively correlated with same sex and two girls, but negatively correlated with two boys. Both the first and second stage regressions include fixed effects for districts $\lambda_{j}$ and survey years $\mu_{s}$. Also, in order to avoid potential biases in the estimation of the standard errors, an arbitrary structure of covariance is allowed by computing clustered robust standard errors at the primary sample unit (PSU) level. ${ }^{17}$

Furthermore, since the same sex binary variable is easily decomposed into two variables indicating the sex composition of the first two children, namely two boys and two girls, an overidentified model with these two instruments and one endogenous variable can be estimated by the following first-stage regression:

$$
\hat{F}_{i j s}=\alpha_{0}+\alpha_{1}(\text { twogirls })_{i j s}+\alpha_{2}(\text { twoboys })_{i j s}+\alpha_{3} b_{1}+\alpha X_{i j s}^{\prime}+\mu_{s}+\lambda_{j}+\nu_{i j s}
$$

\footnotetext{
${ }^{17}$ The primary sampling units (PSUs) are geographically defined area units, which are selected with a probability proportional to size. The PSUs are already constructed in all the LSMS surveys and also in the DHS.
} 
In this specification, either $b_{1}$ or $b_{2}$ must be dropped from the list of covariates because $b_{1}, b_{2}$, two boys and two girls are linearly dependent. Thus, I chose to drop $b_{2}$. It is important to clarify that the results are not sensitive to this choice, or to the elimination of both $b_{1}$ and $b_{2}$, as is shown in the first-stage results presented in the following section.

\section{$7 \quad$ Results}

\section{$7.1 \quad$ First-Stage}

Before examining the effect of fertility on parental labor-force participation, it is important to estimate the prevalence of son preference and mixed-sex preference among Albanian parents. Apart from the raw estimation analysis used to test the relevance condition of the instruments, this section examines in more depth the relevance of Same sex, Two girls and Two boys as instruments for the fertility decision through the first-stage estimation. Table 7 reports the first-stage results linking sex-mix and fertility, where columns (1) to (3) show the results for the just-identified models without covariates, columns (4) to (6) show the results after adding covariates, and column (7) shows the results for the over-identified model with covariates. The top half of the table (Panel A) gives the estimation results for the sample of mothers, while bottom half (Panel B) gives the results for the sample of fathers (husbands or partners of married women).

The results from the first-stage estimation in column (1) suggest that mothers with two children of the same sex have on average 0.22 more children than mothers with children of mixed sex. The instrument Same sex seems to be much stronger for the case of Albania compared to the one reported by Angrist and Evans (1998) and Cruces and Galiani (2007), who find that mothers with two children of the same sex have only 0.07 more children on average. ${ }^{18}$ Moreover, the results in columns (2) and (3) show that the effect of sibling sex composition on fertility is even much stronger if the first two children are girls, but weaker if they are boys.

\footnotetext{
${ }^{18}$ Following Angrist and Evans (1998), if the indicator variable More than 2 children is used as a dependent variable in the first-stage estimation, I obtain very similar results which are significant at the 1 percent level and in each case the F-statistic on the excluded instruments is higher than 10. Compared to Angrist and Evans (1998), who find that the effect of the Same sex instrument to be around 6 percentage points, my first-stage estimates using the indicator More than 2 children seem to be much stronger. For instance, I find that Albanian mothers with two first children of the same sex are estimated to be 13.1 percentage points more likely to have a third child. This estimate rises up to 25.5 percentage points if the first two children are girls, which is bery big. On the contrary, I find that mothers with two boys as first children are on average 7.7 percentage points less likely to have a third child. These results are available upon request.
} 
More specifically, having two girls in an Albanian household increases on average the number of children ever born by 0.47 . This coefficient is twice as large as the coefficient for Same sex, which means that the instrument Two girls is better capturing the exogenous variability in fertility. On the contrary, having two boys decreases the number of children ever born by about 0.16 , which suggest that the parents are less likely to have additional children following sons. All these results are significant at the 1 percent level of significance and in each case the F-statistic on the excluded instruments is higher than 10, considered to be the rule of thumb threshold by Stock et al., (2002).

The next three columns (4) to (6) present similar results after controlling for several covariates such as parent's age, parent's age squared, parent's age at first birth, parent's years of education and also whether the first and the second child are boys, boy1st and boy2st. After the inclusion of these covariates, the instruments Same sex and Two girls have still a positive and statistically significant impact on fertility and the magnitude of the estimates remains pretty unchanged. More specifically, having children of the same sex increases fertility by 0.22 , but having two girls leads to even a bigger increase which reaches up to $0.43 .{ }^{19}$ These estimates are significant at the 1 percent level, their F-statistics on the excluded instruments are above 10 and their Partial R-squared on the excluded instrument are 0.02 and 0.04, respectively. Conversely, the first-stage estimate in column (6) that uses Two boys as an instrument becomes zero in magnitude and it is not statistically significant anymore. In addition, the R-squared from this specification is zero, which clearly indicates that Two boys is a weak instrument in the context of Albania. For this reason, it will not be used in the second-stage estimation.

Lastly, the first-stage estimates of the over-identified model in column (7), which uses both Two girls and Two boys as instruments, also indicate that having two girls increases the number of children by 0.43 on average and this result is statistically significant at the 1 percent level. On the contrary, having two boys does not seem to produce an effect on the number of children and the result is also statistically insignificant, proving to be a weak instrument once more. Thus, the over-identified specification is neither a good candidate for the second-stage estimation.

As a whole, the first-stage results in Table 7 confirm once more that Albanian parents have

\footnotetext{
${ }^{19}$ This is also equivalent to an increase of 24 percentage points in the probability of having a third child when the indicator More than 2 children is used as a measure for fertility. This coefficient is three times bigger than the one found by Angrist and Evans (1998) -7.1 percentage points in the U.S.- and five times bigger than the one found by Cruces and Galiani (2007) -5.3 percentage points for married women in Argentina and 4.6 percentage points for married women in Mexico-.
} 
a strong preference for having sons. In particular, having two girls increases the likelihood of having an additional child, while having two boys seems to have no effect on fertility after controlling for several covariates. Even though the instrument Same sex seems to have a positive and statistically significant effect on fertility, it does not mean that Albanian parents prefer to balance their children's sex-composition because this variable is only capturing the variability generated by Two girls, as Two boys is a weak instrument. Therefore, the second-stage estimation will be based mainly on the exogenous variability of the instrument Two girls, but the instrument Same Sex will be used again as a robustness check. The corresponding first-stage estimates for the sample of fathers are almost exactly the same as the ones for the sample of mothers.

\subsection{Main Results: OLS and Second-Stage}

This section presents the main results of the effect of fertility on parental labor-force participation. Basically, the instrument sibling sex composition is used to measure the effect of fertility on different measures of employment for the parents. The second-stage results are estimated separately for the mothers and the fathers because women and men in Albania differ substantially in the type and amount of labor they supply. Tables 8 and 9 report the OLS estimates in column (1) and two sets of IV estimates in columns (2) and (3) using Same sex and Two girls as instruments, for the sample of mothers and fathers, respectively. ${ }^{20}$ All the specifications include the same set of control variables as in Table 7. The upper panel of Tables 8 and 9 not only reports the estimates for total labor-force participation, but also presents the estimates for parent's on-farm, off-farm and own account labor supply separately. While, the bottom panel reports estimates for hours worked per week, second occupation and monthly labor earnings. ${ }^{21}$

The OLS estimates in Table 8 indicate that the correlation between fertility and mother's likelihood of working (including off-farm, on-farm and self-employed work) is very small and not

\footnotetext{
${ }^{20}$ The first-stage specifications of columns (4) and (6) in Table 7, which use Same sex and Two girls as instruments for fertility, are the ones selected for the second-stage estimation because these are the ones that proved to be the strongest instruments after controlling for covariates.

${ }^{21}$ The variables presented in the bottom panel of Tables 8 and 9 such as hours worked per week, second occupation and montlhy labor income are only available in the Albanian LSMS surveys, but not in the Albanian DHS survey. For this reason, the sample of mothers is reduced to 4862 observations and the sample of fathers to 4530 observations. The first-stage estimates for these reduced samples are very similar to the ones showed in Table 7 , but very slightly smaller in magnitude. Once again Two girls and Same Sex prove to be valid instruments for fertility, while Two boys seems to be a weak instrument. The first-stage estimates for these samples are reported in Table A-4 in the Appendix.
} 
statistically significant. Having an additional child (third or higher parity) seems to reduce the likelihood of working by less than 1 percentage point (0.6 pp). The correlation between fertility and other measures of mother's labor supply such as hours worked per week and whether she has a second occupation are also around zero in magnitude and not precisely estimated. However, if the analysis is separated by type of work, the presence of an additional child has a negative and statistically significant correlation with mother's likelihood of working off-farm and on own account, but it has a positive and statistically significant correlation with mother's likelihood of working on-farm. The point estimate for mother's monthly earnings is negative and statistically significant. This coefficient is quite substantial in magnitude given that it represents around 12 percent of the average monthly labor income in the sample of mothers.

In contrast to the results for mothers, OLS estimates for the sample of fathers in Table 9 suggest that having an additional child increases father's likelihood of working (+1.2 pp) and also their likelihood of having a second occupation (+0.8 pp). Even though these coefficients are quite small in magnitude, they are precise enough to be statistically different from zero. In addition, the correlation between fertility and father's hours worked per week is also slightly above zero, but not precisely estimated. Nonetheless, similarly to mothers, the estimation by type of work shows that having another child reduces father's likelihood of working off-farm and on own account, but it increases the likelihood of working on-farm. All these results are very precisely estimated. Finally, the correlation between fertility and father's monthly earnings is negative and statistically significant.

Although the OLS estimates for the effect of fertility on labor supply suggest that parent's withdrawal form the labor market or their further participation in it, depend on the type of job they are performing they should be taken with caution because they could well be biased. For this reason, the endogeneity in the fertility decision is treated by using the Instrumental Variables (IV) method. After correcting for this problem, the second-stage results tell a completely different story. Once Same sex and Two girls are used as instruments, some of the IV estimates of the effect of fertility on parental labor-supply change sign and magnitude compared to the OLS estimates.

The set of IV estimates for the sample of mothers in Table 8, which use Same sex and Two girls as instruments, indicate that a mother's likelihood of working increases with the decision of having an additional child, but these coefficients are both imprecisely estimated. Similar results 
are obtained when the dependent variable is mother's monthly labor income and whether she has a second occupation. Moreover, when the analysis is done by type of work, the estimates using Same sex show that the effect of fertility on mother's likelihood of working off-farm, on-farm and on own account are also positive, but none of these coefficients are significantly significant.

However, the IV estimates using Two girls indicate that there is a positive effect of fertility on mother's likelihood of working off-farm and this coefficient is statistically significant at the 5 percent level. More specifically, having an additional child increases on average a mother's likelihood of working off-farm by 5 percentage points, which represents a 30 percent increase in the average participation rate of work off-farm for mothers. But, the presence of an additional child does not seem to have a statistically significant impact on mother's likelihood of working on-farm and on own account. In addition, the two sets of IV estimates indicate that having an additional child seems to also have a positive and statistically significant impact on mothers hours worked per week. To be more precise, each additional child increases the working time of a mother by about $4.4-4.6$ hours per week. This coefficient is quite big given that it represents 26 percent of the average working time of the mothers in the sample. ${ }^{22}$

The labor-supply effects estimated using the sample of fathers are quite similar to those for the mothers. Again, the two sets of IV estimates in Table 9 indicate that having an additional child increases a father's likelihood of working, but this coefficient seems to be imprecisely estimated. Also, the estimates using Same sex show that the effect of fertility on father's likelihood of working off-farm, on-farm and on own account are also positive, but none of them are significantly different from zero. However, the IV estimates using Two girls indicate that having an additional child increases father's likelihood of working off-farm (+6.7 pp) and also their likelihood of having a second occupation $(+4.0 \mathrm{pp})$. These two coefficients are statistically significant at the 5 and 10 percent level of significance, respectively. On the other hand, the birth of another child has a negative effect on father's monthly labor earnings and hours worked

\footnotetext{
${ }^{22}$ A distinguishable characteristic of Albania during the years of this study is the combination of low fertility with low female participation rates. Female labor force participation has stagnated or even decreased during the last two decades despite a significant drop in fertility rates. The combination of these two stylized facts does not necessarily mean that there exists an inverse relation between fertility and female labor supply, as it has been stated in various developed countries. A study from Da Rocha and Fuster (2006) corroborates in part this mechanism. These authors find that labor market frictions determine how employment and fertility are associated across economies. In particular, they find that fertility and employment are positively associated across economies with low employment ratios (low probability of finding a job). On the other hand, they find that fertility and employment are negatively associated across economies with high probability of finding a job. Their findings also suggest that the sign of this relationship could change as the job-finding rate of females increases.
} 
per week, but the coefficient on labor earnings is the only one precisely estimated. These results suggest that having an additional child causes a 17-percent increase in father's labor supply, but also a 24-percent reduction in his earnings.

Therefore, a plausible interpretation of the positive effect found between fertility and parental labor supply in Albania is that having an additional child induces parents with at least two children to work more for somebody rather than a household member, which means that they increase their labor supply in the non-agricultural sector. But, why would parents increase family size in order to augment their chances of being employed in a kind of job that might be considered as more stable or with a greater formality? One way of interpreting these findings is by looking at the payment of a job as a bundle of services, such as wages, schedule flexibility, social status, security etc. Thus, an increase in fertility would not only increase the cost of time intensive activities but also the attractiveness of some jobs (scheme of payments) that are compatible with bigger family size versus others. For the case of mothers, this type of job might be more temporary than permanent due to the fact that part-time work tends to be higher for temporary jobs than for permanent, and also because part-time work is easier to combine with motherhood tasks. Conversely, for the case of fathers this type of job might be more permanent than temporary due to the better benefits, such as higher earnings among others.

\subsection{Heterogeneity Analysis}

In this section, I examine whether the effect of fertility on parental labor-force participation may be sensitive to certain sub-populations in each sample. For instance, Gronau (1988) and Angrist and Evans (1998) suggest that the relationship between labor supply and childbearing is likely to differ by women's educational level. They find that the labor supply of less educated women is more sensitive (more negative) to the presence of children than the labor supply of more educated women. Angrist and Evans (1998) also explore how the female labor-market consequences of childbearing vary with the earnings of the husbands. They find that the effect of fertility on women's labor supply declines in magnitude (less negative) with husbands's earnings.

Moreover, it seems essential from a policy point of view to be able to identify which one of the sub-populations has the greatest response to the effects of fertility on parental labor market outcomes, in particular in relation to income or wealth level. For instance, if there are

significant differences between groups, then a clear identification of those in most need of policy 
intervention could potentially help in the choice of a particular policy, i.e. between benefit increases and tax reductions for families. Therefore, this section examines whether the effect of fertility on parental labor supply varies with: parent's education level, parent's birth cohort and family structure. Tables 10, 12 and 11 report the OLS and IV estimates for the heterogeneity analysis, where the top panels correspond to the estimates for the sample of mothers, while the bottom panels correspond to those for the sample of fathers.

Firstly, Table 10 presents the heterogeneity analysis of the effect of fertility on parental labor supply by parent's educational level. For this analysis, all the parents in the sample are divided into two different groups by taking as a reference their primary school completion: below or completed primary level ( $\leq 8$ years of schooling) and above primary level ( $>8$ years of schooling). This separation is based on two simple facts. First, the average schooling years for mothers and fathers with at least two children in Albania are 10 and 11, respectively; and second, parents who have completed primary school (8 years) represent about 50 percent of the observations in each sample. The IV estimation results in Table 10 indicate that the effect of fertility on parental labor supply is positive, but in most of the cases they are statistically insignificant for both levels of education. However, the IV coefficients on hours worked per week for mothers belonging to the lowest educational level have a positive sign and are statistically significant at the 10 percent level. In addition, the IV coefficient on second occupation for fathers belonging to the lowest educational level also has a positive and statistically significant effect at the 10 percent level. On the contrary, the labor supply effects for parents with a higher level of education are imprecisely estimated. Thus, it seems reasonable to argue that fertility increases labor-force participation for less educated parents and, hence, possibly less economically well parents in order to respond to an increased demand in the household, namely need for income.

Secondly, estimates in Table 11 explore whether the effect of fertility on parental labor-force participation is likely to vary with parent's birth cohort. The birth cohort threshold is set at birth years, which allow the division of the main samples of mothers and fathers with at least two children into two subsamples of similar size. On the one hand, the sample of mothers is divided between mothers born before 1972 (included) and mothers born after 1972. On the other hand, the sample of fathers is divided between fathers born before 1966 (included) and those born after 1966. ${ }^{23}$ The IV estimates in Table 11 for mothers of younger cohorts show a

\footnotetext{
${ }^{23}$ The average year of birth in the sample of mothers aged 20 to 49 years old with at least two children is
} 
positive and statistically significant effect of fertility on hours worked per week at the 1 percent level. Also, the IV estimates for younger fathers show a positive and statistically significant effect on father's likelihood of having a second occupation as a consequence of childbearing. On the contrary, the coefficients on fertility for mothers and fathers of older cohorts are lower in magnitude and statistically insignificant. Hence, I can confirm that there exists a degree of heterogeneity in the link between fertility and labor market outcomes by parent's birth cohort, where the positive effect seems to be driven mostly by younger cohorts. This result also suggests that the positive effect of fertility on parental labor-supply is not driven by parents whose older children in the household are taking care of the younger siblings, which is reassuring in terms of the exclusion restriction.

Lastly, it can be argued that the family structure in developing countries is quite different from developed countries. The negative result between fertility and labor supply found mostly in developed countries is based on the assumption that nuclear families formed by two adults, namely, the father and the mother, are of the major type. Therefore, having an additional child increases the time cost of parents which in turn decreases their labor supply, especially mother's labor supply. However, this result might not necessarily hold in developing countries, where the family structure can be characterized more by extended families. Extended families are composed by several generations consisting of grandparents, aunts, uncles, and cousins all living nearby or in the same household. A typical example is a married couple that lives with either the husband's or wife's parents. Thus, if indeed the parents have help in the household from the grandparents, they might not be forced to leave the workforce when they have an additional child. Under this scenario, the effect of fertility on parental labor supply depends on the extent of substitutability between the time spent by grandparents and parents in childcare and household chores. In response to an increase in fertility, grandparents may adjust their time allocation by supplying more time in childcare and household chores. ${ }^{24}$ As a result, the relationship between fertility and labor supply might not be inverse in the case of developing countries.

1972, while the average year of birth in the sample of fathers (husbands or partners of the married mothers) is 1966. Mothers born before 1972 (included) represent 49.5 percent of the sample, while mothers born after 1972 represent 50.5 percent of the sample. Similarly, fathers born before 1966 (included) represent 50.2 percent of the sample, while fathers born after 1972 represent 49.8 percent of the sample.

${ }^{24}$ Gong and van Soest (2002) find that the presence of another female adult in the household increases the labor supply of mothers who have young children. 
Extended families with three generations are very common in rural Albania (Gjonça et al, 2008). For instance, the datasets used in this paper indicate that around 38 percent of the households live in extended families. This number is slightly higher in rural areas where it increases up to 42 percent. Several demographic studies have documented the rather particular nature of the Albanian family structure, characterized by extended families (Gjonça et al, 2008; King and Vullnetari, 2013). During most of the 20th century, the extended family in Albania was the basic single residential unit and economic entity. Basically, it was formed by a married couple with their married sons and their offspring, as well as any unmarried daughters. The size of these families was very large, and by the end of WWII some numbered as many as 60 to 70 members. In terms of care duties, particular responsibility was vested in the youngest son to ultimately take care (with his wife bearing the brunt) of elderly or sick parents, according to Albanian tradition and custom. The youngest son is thus known as the "son of old age". Given this context, it could be argued that extended families in Albania are a given characteristic of society, which means that individuals do not actually choose to live in one. In addition, using the 2002 Albanian LSMS which contains detailed information on the fertility history of mothers from old birth cohorts, it is possible to calculate the proportion of parents in extended families living with their sons, by their son's birth order. Indeed, Figure 5 shows that most of the parents in extended families live with their youngest married son (61.1 percent).

Table 12 reports the OLS and IV estimates of the effect of fertility on parental labor supply, conditional on the family structure. For this heterogeneity analysis both samples (mothers and fathers) are divided into two types of households: those that have grandparents older than 50 years old living in the same household as the parents (extended families) and those that do not (non-extended families). On the one hand, the IV estimates in Table 12 suggest that mothers living in extended families experience the largest effects of fertility on labor supply. More specifically, the IV estimates for mothers living in extended families indicate a positive and statistically significant effect of fertility on the likelihood of working off-farm and also on hours worked per week. In contrast, there is no statistically significant link between additional fertility and labor supply for mothers living in non-extended families. On the other hand, father's who live in non-extended families seem to be more likely of having a second occupation than those that live in extended families and this estimate is the only precisely estimated. Henceforth, it is worth arguing that fertility increases labor supply for fathers in non-extended families because 
in these families it is very likely that the mother must stay in the household to take care of the children as she does not have extra help from the grandparents or other relatives. Moreover, it can also be argued that fertility increases the participation of mothers in extended families because they have help in the household in terms of childcare from the grandparents and, thus, mothers might not be forced to leave the labor market.

\subsection{Two possible mechanisms}

Why does fertility affect labor supply of either mothers and fathers positively in this developing country? In the previous sections, I find that having an additional child affects positively the labor supply of both mothers and fathers and that this result varies by certain sub-populations in both samples. Taking into account the heterogeneity analysis, I propose two possible mechanisms behind the results for the case of Albania.

The first potential mechanism might be due to greater financial costs of feeding more children. Basically, the idea is that an increase in fertility faces households to a tighter budget constraint which reduces the standard of living in the household and gives an incentive to parents to increase their labor-force participation. In line with this hypothesis, the heterogeneity analysis in the previous section suggests that almost the entire positive effect can be attributed to labor market responses by parents which are less educated and younger. From this result, it is plausible to deduce that these parents are also economically less favoured. Naturally, fertility can affect parental labor supply, especially maternal labor supply, in two directions: on the one hand, it can provoke parents to withdraw from the labor market due to child caring; on the other hand, given that modern child caring is assumed to be very expensive it can also stimulate parents to participate in the labor market in order to finance basic expenditures on their children. Therefore, for the case of Albania the latter constraint might be stronger than the former. It is possible to suggest that poorer, less educated and younger parents are the ones that need to provide more for their families compared to richer, more educated and older parents. This mechanism could be particularly true for developing countries such as Albania because in this context households generally act under tighter budget constraints where a large share of income is devoted to food and other basic needs. For instance, in Table 6 it can be observed that Albanian households dedicate more than half of their budget to food expenditure (54.8 percent).

The second potential mechanism might be related to the presence of extended families. 
Childcare provided by non-parental adults (i.e grandparents) may act as a substitute for parental childcare in developing countries. Several previous studies have examined the effect of family structure on female labor supply and they have found that the presence of grandparents in the household increases the labor supply of women who have children (Wong and Levine, 1992; Sasaki, 2002; and Gong and van Soest, 2002, Posadas and Vidal-Fernandez, 2012). In the context of Albania, where extended families are quite prevalent and professional childcare is quite rare, non-parental household members such as grandparents may be the perfect candidates for taking care of the children. Conforming to the heterogeneity analysis by family structure in Table 12, the positive effect of fertility on mother's labor-force participation is largest for those living in extended families. Another interesting and important result is that the positive effect of fertility on father's labor supply is mostly driven by those living in non-extended families. This result suggests that, in non-extended families, parents do not count with childcare provided by grandparents and therefore the mother has to stay in the household while the father probably searches for a second occupation.

In order to shed some further light on these two mechanisms, in Table 13 I examine whether the effect of fertility on family expenditure per capita depends on family structure and the wealth level of the household. For this estimation, households are pooled together into five expenditure quintiles i.e. all households in quintile 1 belong to the lowest expenditure level. Table 13 provides some descriptive statistics and IV estimates using Same sex and Two girls as instruments on the five different quintiles. As one would expect, parents in poorer quintiles are more likely to be younger, to have children at a younger age, to have a third child and to live in rural areas, but they are less likely to live in an extended family. Moreover, having an additional child reduces the family expenditure per capita in all quintiles and this estimate is precisely estimated when using Two girls as instrument. This result suggests that an increase in fertility leads to a tighter budget constraint in the household. When these estimates are analyzed by family structure, I find that the negative effect of fertility on expenditure percapita is smaller in magnitude (less negative) for extended families and it is only statistically significant in two quintiles. On the contrary, non-extended families experience larger negative effects of fertility on family expenditure per-capita and these results are statistically significant in all quintiles. Also, the estimates for non-extended families show a stronger negative effect in the lowest expenditure quintiles. These results are in line with the reasoning above and seem 
to support the view that higher fertility associated with greater child costs and lower childcare costs provided by grandparents in extended families is an important factor that influences the labor supply decision of parents in Albania.

\section{Conclusion}

The purpose of this paper is to investigate whether there is a causal effect of fertility on parental labor-force participation in the context of a developing country in the Balkan region, such as Albania. In order to address the endogeneity in the fertility decision, I apply an Instrumental Variables (IV) approach first introduced by Angrist and Evans (1998), which exploits Albanian parental preference for having sons as an exogenous source of variation in the fertility decision. Using a repeated cross-section of Albanian mothers and fathers with at least two children that still live in the household, I find that Albanian parents have a strong and persistent preference for having sons. In particular, the results from the first-stage specifications suggest that having Two girls increases on average the number of children ever born by 0.43 , which is equivalent to an increase of 24 percentage points (almost 60 percent of the sample mean) in the likelihood of having an additional child. These first-stage estimates are very precisely estimated.

While most of the previous studies on this topic have found a negative relationship between fertility and labor supply, especially for women's labor supply, there are also some studies that contradict these findings and indicate a positive relation (Priebe, 2010; Porter and King, 2010; Bloom et al, 2009). Hence, in the same line as the latter group of studies, the point estimates reported in this paper suggest that fertility has a positive effect on parental labor-force participation in the context of Albania. More precisely, for the sample of mothers I find that having an additional child (third or higher order) increases on average a mother's likelihood of working off-farm by 5 percentage points and it also increases the working time by around 4.4 hours per week on average. These results are statistically significant at the 5 percent level. In addition, the heterogeneity analysis suggests that the labor-market consequences of fertility are more likely to be driven by poorer, less educated, and younger mothers, who also happen to live in extended families.

Similarly relevant is the finding that fathers also change positively their labor-market behaviour in response to a change in family size. In particular, having an additional child increases father's likelihood of working off-farm by 6.7 percentage points, and also their likelihood of hav- 
ing a second occupation by 4 percentage points. These point estimates are statistically significant at the 5 and 10 percent level of significance, respectively. On the other hand, the birth of another child has also a negative effect on father's monthly labor earnings and this coefficient is precisely estimated. In terms of heterogeneity analysis, I also find that less educated, poorer and younger fathers that live in non-extended families are the ones that need to search more for employment as a response to a fertility increase.

These results confirm the common view in labor economics that children are an important determinant of parental labor supply. However, in contrast to findings for developed countries, children might not only restrict the opportunity of parents to participate in the labor market but as well create an incentive to search for employment. In order to shed some light on the mechanisms behind these results, a simple theoretical model that links childcare costs and family structure with fertility and parental labor supply is derived. In line with the predictions of the model, I propose two plausible mechanisms behind the positive effect of fertility on parental labor supply. The first one suggests that an increase in fertility faces households to a tighter budget constraint which reduces the standard of living in the household and gives an incentive to parents to increase their labor-force participation. The second one suggests that childcare provided by non-parental adults (i.e grandparents) may act as a substitute for parental childcare in developing countries, thus, allowing them to increase labor supply as a consequence of further childbearing.

Lastly, the findings in this paper might have important implications in terms of public policy. In many developed countries much attention has been given to the role of child care costs/subsidies, including direct provision of public pre-school, on female labor supply (Blau and Robins, 1988; Conelly, 1992; Kimmel, 1998; Gelbach, 2002). In this paper, I show that an increase in family size might lead to an increase in parental labor supply in the context of a developing country due to greater child costs but also lower childcare costs provided by the presence of grandparents in extended families. Given that households in developing countries, such as Albania, act under tighter budget constraints and that provision of public childcare is quite insufficient and inadequate, one possible public policy intervention could be the implementation of child care subsidies including direct provision of day-care nurseries, public kindergartens and pre-schools. The objective of these interventions would be to substitute non-parental childcare by generating more jobs in the economy and at the same time increasing parental labor-force 
participation, especially for women. This policy might promote economic growth in the long-run in Albania.

\section{References}

[1] Agüero, J. M. and M. S. Marks, (2011) "Motherhood and female labor supply in the developing world evidence from infertility shocks". Journal of Human Resources, 46(4), $800-826$

[2] Angrist, J. and W. Evans, (1998) "Children and their parent's labor supply: evidence from exogenous variation in family size". American Economic Review, 88(3), 450-477

[3] Arnold, F. and Zhaoxiang, L. (1986) "Sex preference, fertility, and family planning in China". Population and Development Review, 12, 221-246.

[4] Becker, G. S., and H. G. Lewis, (1973) "On the Interaction Between Quantity and Quality of Children". Journal of Political Economy, 82, 279-288.

[5] Becker, G. S., and N. Tomes, (1976) "Child Endowments and the Quantity and Quality of Children". Journal of Political Economy, 84, 143-162.

[6] Becker, G. (1985) "Human Capital, Efforts, and the Sexual Division of Labour". Journal of Labour Economics, 3(1), Part 2, January, pp. 33-58.

[7] Blau, D.M. and P.K. Robins (1988) "Child-Care Costs and Family Labor Supply". The Review of Economics and Statistics, 70 (3), 374-381.

[8] Bloom, D. E., D. Canning, G. Fink, and J. E. Finlay (2009) "Fertility, female labor force participation and the demographic dividend". Journal of Economic Growth, 14(2), 79-101

[9] Blunch, Niels-Hugo, Sudharshan Canagarajah, and Dhushyanth Raju. (2001) "The Informal Sector Revisited: A Synthesis Across Space and Time”. Social Protection Discussion Paper Series, N 0119, World Bank.

[10] Bound, J., Jaeger, D. and Baker, R. (1995) "Problems with Instrumental Variables Estimation When the Correlation Between the Instruments and the Endogenous Explanatory Variable is Weak". Journal of the American Statistical Association, 90(430), 443-450 
[11] Bronars, Stephen, and Jeff Grogger (1994) "The Economic Consequences of Unwed Motherhood: Using Twin Births as a Natural Experiment.". American Economic Review, 84(5), $1141-56$

[12] Browning, M., (1992) "Children and household economic behavior". Journal of Economic Literature, 30(3), 1434-75

[13] Cain, Glen, and Martin Dooley (1976) "Estimation of a Model of Labor Supply, Fertility and Wages of Married Women". Journal of Political Economy, 84(4), 179-99

[14] Chun, H., Oh, J., (2002) "An instrumental variable estimate of the effect of fertility on the labour force participation of married women". Applied Economics Letters, 9(10), 631- 634

[15] Coleman, M.T. and J. Pencavel, (1993) "Trends in Market Work Behavior of Women since 1940". Industrial and Labor Relations Review, 46 (4), 653-676

[16] Conelly, R., (1992) "The Effect of Child Care Costs on Married's Women Labor-Force Participation"”. The Review of Economics and Statistics, 74 (1),83-90.

[17] Danaj, Ermira (2014) "Family in Albania as a primary solidarity network". in "Legacy and Change: Albanian transformation from multidisciplinary perspectives", edited by Robert Pichler, LIT Verlag.

[18] Ebenstein, A. (2009) "When is the local average treatment close to the average? evidence from fertility and labor supply". Journal of Human Resources, 44 (4), 955-975

[19] Even, William (1987) "Career Interruptions Following Childbirth". Journal of Labor Economics, 5 (2), 255-277

[20] Fleisher, Belton, and George Rhodes (1979) "Fertility, Womens Wage Rate and Labor Supply". American Economic Review, 69 (1), 14-24

[21] Gelbach, J.B., (2002) "Public Schooling for Young Children and Maternal Labor Supply". American Economic Review, 92 (1), 307-322.

[22] Gjonça, Arjan, Aassve, Arnstein and Mencarini, Letizia (2008) "Trends and patterns, proximate determinants and policies of fertility change: Albania". Demographic Research, 19 (11). 261-292 
[23] Goldin, Claudia, and Solomon Polachek (1987) "Residual Differences by Sex: Perspectives on the Gender Gap Earnings". American Economic Review, 77 (2). 143-51

[24] Gong, Xiaodong, and Arthur van Soest (2002) "Family structure and female labour supply in Mexico city". Journal of Human Resources, 37(1), 146-157

[25] Gronau, Reuben (1973) “The Intrafamily Allocation of Time: The Value of the Housewives' Time". American Economic Review, 63. 634-51

[26] Gronau, Reuben (1973) "Sex-Related Wage Differentials and Womens Interrupted Careers the Chicken or the Egg". American Economic Review, 6 (3). 277-301

[27] Heckman, James (1974) "Shadow Prices, Market Wages and Labor Supply". Econometrica, 42. $679-94$

[28] Heckman, James, and Robert Willis (1977) "A Beta-Logistic Model for the Analysis of Sequential Labor Force Participation by Married Women". Journal of Political Economy, 85 (1). $27-58$

[29] International Monetary Fund (2006) "Albania: Poverty Reduction Strategy Paper - Annual Progress Report". In Albania: Poverty Reduction Strategy Paper - Annual Progress Report. $U S A$.

[30] INSTAT (Albania, Institute for Statistics) (2004) "People and Work in Albania". 2001 Population and Housing Census. Tirana: INSTAT Albania.

[31] INSTAT (Albania, Institute for Statistics) (2014) "Women and Men in Albania". Tirana: INSTAT Albania.

[32] Jacobsen, Joyce, James Wishart Pearce III, and Joshua Rosenbloom (1999) "The Effects of Childbearing on Married Women Labor Supply and Earnings: Using Twin Births as a Natural Experiment". Journal of Human Resources, 34 (3). 449-74

[33] Killingsworth, M. and J. Heckman (1986) "Female Labor Supply: A Survey". in Orley Ashenfelter and Richard Layard (eds.), Handbook of Labor Economics, Vol. 1. Amsterdam: North-Holland. 
[34] Kimmel, J., (1998) "Child Care Costs as a Barrier to Employment for Single and Married Mothers". The Review of Economics and Statistics, 80 (2), 287-299.

[35] Klerman, J. A. (1999) "Us abortion policy and fertility". American Economic Review, 89 (2), 261-264

[36] Korenman, Sanders, and David Neumark (1992) "Marriage, Motherhood and Wages". Journal of Human Resources, 27 (2), 233-255

[37] Kuvendi Popullor (1976) "The Constitution of the Socialist Republic of Albania". Article 14: $28-41$

[38] Lee, D. (2002) "Fertility and Female Labor Supply in Rural China". Working Paper

[39] Lehrer, Evelyn (1992) "The Impact of Children on Married Womens Labor Supply: BlackWhite Differentials Revisited". Journal of Human Resources, 27 (3), 422-444

[40] Lundberg, S. and E. Rose (2000) "Parenthood and the Earnings of Married Men and Women". Labour Economics, 689-710

[41] Mammen Kristin, and Christina Paxson. (2000) "Women's Work and Economic Development". The Journal of Economic Perspectives, 14 (4): 141-164.

[42] Millimet, D. L. (2000) "The Impact of Children on Wages, Job Tenure, and The Division of Household Labour". The Economic Journal, 110(March), 139-57.

[43] Nakamura, Alice, and Masao Nakamura (1992) "The Econometrics of Female Labor Supply and Children". Econometrics Review, 11 (1), 1-71

[44] Porter, M. and E. M. King (2010) "Fertility and Women's Labor Force Participation in Developing Countries". Working paper

[45] Posadas, J., and M. Vidal-Fernandez (2012) "Grandparents' Child Care and Female Labor Force Participation". Working Paper 6398, Institute for the Study of Labor, Bonn.

[46] Priebe, Jan (2010) "Child Costs and the Causal Effect of Fertility on Female Labor Supply: An investigation for Indonesia 1993-2008". Courant Research Centre: Poverty, Equity and Growth, Discussion Papers, No. 45 
[47] Rosenzweig, M. R. and K. I. Wolpin (1980) "Life-cycle Labor Supply and Fertility: Causal Inferences From Household Models". The Journal of Political Economy, 88(2), 328-348

[48] Rosenzweig, M. R. and K. I. Wolpin (2000) "Natural" natural experiments" in economics". Journal of Economic Literature, 38(4), 827-874

[49] Sasaki, Masaru (2002) "The causal effect of family structure on labor force participation among Japanese married women". Journal of Human Resources, 37(2), 429-440

[50] Schultz, T. Paul (1978) "The Influence of Fertility on Labor Supply of Married Women: Simultaneous Equation Estimates". In Ronald Ehrenberg, Ed., Aspects of Labor Economics. Greenwich, CT: JAI Press, 273-351

[51] Schultz, T. Paul (2009) "How does family planning promote development? evidence from a social experiment in Matlab, Bangladesh 1977-1996". Yale University, Economic Growth Center, New Haven, Conn.

[52] Tarifa, Fatos (1996) "Disappearing from Politics: Social Change and Women in Albania". Women in the Politics of Post-communist Eastern Europe. New York: M.E. Sharpe, Inc.

[53] UNFPA (2012) "Sex imbalances at birth in Albania". World Vision, Tirane, Albania

[54] Wong, Rebeca, and Ruth E. Levine (1992) “The effect of household structure on women's economic activity and fertility: evidence from recent mothers in urban Mexico". Economic Development and Cultural Change, 41 (1), 89-102

[55] Wooldridge, J. (2003) "Chapter 15: Instrumental Variables Estimation and Two-stage Least Squares". In: Introductory Econometrics, A Modern Approach, Second Edition. SouthWestern Publishing

[56] World Bank. (2011) "World Development Report 2012: Gender Equality and Development". Washington, D.C.: World Bank

[57] Zickel, R. and Iwaskiw R. W. (1994) "Albania Country Study". Second edition, Headquarters, Department of the Army, Library of Congress, US 
Table 1: Descriptive Statistics for Mother's Fertilty in Albania (2002 - 2012)

\begin{tabular}{|c|c|c|c|c|c|}
\hline Variables & Observations & Mean & $\begin{array}{l}\text { Standard } \\
\text { Deviation }\end{array}$ & Min & $\operatorname{Max}$ \\
\hline \multicolumn{6}{|c|}{ Sample: Mothers aged 20 to 49 years old with 2 or more children younger than 18 years old } \\
\hline $\begin{array}{l}\text { Fertility } \\
\qquad \text { (Number of children ever born) }\end{array}$ & 7480 & 2.600 & $(0.871)$ & 2 & 9 \\
\hline $\begin{array}{l}\text { More than } 2 \text { children } \\
\quad(=1 \text { if mother had } 3 \text { or more children) }\end{array}$ & 7480 & 0.418 & $(0.493)$ & 0 & 1 \\
\hline $\begin{array}{l}\text { First child boy } \\
\text { (=1 if first child was a boy) }\end{array}$ & 7480 & 0.492 & $(0.499)$ & 0 & 1 \\
\hline $\begin{array}{l}\text { First child girl } \\
\qquad(=1 \text { if first child was a girl) }\end{array}$ & 7480 & 0.508 & $(0.499)$ & 0 & 1 \\
\hline $\begin{array}{l}\text { Second child boy } \\
\qquad(=1 \text { if second child was a boy) }\end{array}$ & 7480 & 0.514 & $(0.499)$ & 0 & 1 \\
\hline $\begin{array}{l}\text { Two boys } \\
\text { (=1 if first two children were boys) }\end{array}$ & 7480 & 0.254 & $(0.435)$ & 0 & 1 \\
\hline $\begin{array}{l}\text { Two girls } \\
\text { (=1 if first two children were girls) }\end{array}$ & 7480 & 0.247 & $(0.431)$ & 0 & 1 \\
\hline $\begin{array}{l}\text { Same sex } \\
\qquad(=1 \text { if first two children have the same sex) }\end{array}$ & 7480 & 0.502 & $(0.500)$ & 0 & 1 \\
\hline $\begin{array}{l}\text { Mixed sex } \\
\qquad(=1 \text { if first two children have different sex })\end{array}$ & 7480 & 0.497 & $(0.500)$ & 0 & 1 \\
\hline
\end{tabular}

Notes: The data used are the 2002 LSMS, the 2005 LSMS, the 2008-09 DHS and the 2012 LSMS 
Table 2: Descriptive Statistics for Mother's Labor-Supply in Albania (2002 - 2012)

\begin{tabular}{|c|c|c|c|c|c|}
\hline Variables & Observations & Mean & $\begin{array}{l}\text { Standard } \\
\text { Deviation }\end{array}$ & Min & $\operatorname{Max}$ \\
\hline \multicolumn{6}{|l|}{ Mother's Labor Supply } \\
\hline Worked in last 7 days & 7445 & 0.444 & $(0.496)$ & 0 & 1 \\
\hline Worked off-farm & 7445 & 0.163 & $(0.369)$ & 0 & 1 \\
\hline Worked on-farm & 7445 & 0.217 & $(0.412)$ & 0 & 1 \\
\hline Self-employed & 7445 & 0.066 & $(0.249)$ & 0 & 1 \\
\hline Second occupation & 4903 & 0.014 & $(0.120)$ & 0 & 1 \\
\hline Hours/week (total) & 4903 & 16.60 & $(21.24)$ & 0 & 112 \\
\hline Hours/week (off-farm) & 4903 & 7.17 & $(16.20)$ & 0 & 70 \\
\hline Hours/week (on-farm) & 4903 & 7.52 & $(15.64)$ & 0 & 70 \\
\hline Hours/week (self) & 4903 & 2.35 & $(11.15)$ & 0 & 112 \\
\hline Monthly labor income & 4903 & 50166.4 & $(114456)$ & 0 & 1217661 \\
\hline \multicolumn{6}{|c|}{ Other characteristics of mothers } \\
\hline Age & 7480 & 35.04 & $(5.691)$ & 20 & 49 \\
\hline Age at first birth & 7480 & 23.22 & $(3.489)$ & 14 & 41 \\
\hline Years of education & 7404 & 10.47 & $(3.135)$ & 0 & 21 \\
\hline Rural & 7480 & 0.482 & $(0.499)$ & 0 & 1 \\
\hline Household size & 7480 & 5.188 & $(1.478)$ & 1 & 16 \\
\hline Extended family & 7480 & 0.381 & $(0.485)$ & 0 & 1 \\
\hline Marital status (married) & 7480 & 0.980 & $(0.137)$ & 0 & 1 \\
\hline Muslims & 7480 & 0.816 & $(0.387)$ & 0 & 1 \\
\hline Catholics & 7480 & 0.081 & $(0.273)$ & 0 & 1 \\
\hline Orthodox & 7480 & 0.067 & $(0.251)$ & 0 & 1 \\
\hline Coastal region & 7480 & 0.264 & $(0.440)$ & 0 & 1 \\
\hline Central region & 7480 & 0.282 & $(0.450)$ & 0 & 1 \\
\hline Mountain region & 7480 & 0.291 & $(0.454)$ & 0 & 1 \\
\hline Tirana region & 7480 & 0.161 & $(0.367)$ & 0 & 1 \\
\hline
\end{tabular}

Notes: The data used are the 2002 LSMS, the 2005 LSMS, the 2008-09 DHS and the 2012 LSMS 
Table 3: Descriptive Statistics for Father's Labor-Supply in Albania (2002 - 2012)

\begin{tabular}{|c|c|c|c|c|c|}
\hline Variables & Observations & Mean & $\begin{array}{l}\text { Standard } \\
\text { Deviation }\end{array}$ & Min & Max \\
\hline \multicolumn{6}{|l|}{ Father's Labor Supply } \\
\hline Worked in last 7 days & 5496 & 0.787 & $(0.409)$ & 0 & 1 \\
\hline Worked off-farm & 5496 & 0.393 & $(0.488)$ & 0 & 1 \\
\hline Worked on-farm & 5496 & 0.236 & $(0.424)$ & 0 & 1 \\
\hline Self-employed & 5496 & 0.197 & $(0.398)$ & 0 & 1 \\
\hline Second occupation & 4566 & 0.058 & $(0.234)$ & 0 & 1 \\
\hline Hours/week (total) & 4566 & 34.23 & $(23.06)$ & 0 & 112 \\
\hline Hours/week (off-farm) & 4566 & 18.50 & $(23.43)$ & 0 & 99 \\
\hline Hours/week (on-farm) & 4566 & 9.10 & $(18.71)$ & 0 & 99 \\
\hline Hours/week (self) & 4566 & 7.63 & $(19.09)$ & 0 & 112 \\
\hline Monthly labor income (old leks) & 4566 & 191841.9 & $(333208.7)$ & 0 & 12000000 \\
\hline \multicolumn{6}{|l|}{ Other characteristics of fathers } \\
\hline Age & 5737 & 39.92 & $(5.855)$ & 22 & 64 \\
\hline Age at first birth & 5737 & 28.33 & $(4.177)$ & 15 & 58 \\
\hline Years of education & 5541 & 11.08 & $(3.426)$ & 0 & 20 \\
\hline Rural & 5737 & 0.478 & $(0.499)$ & 0 & 1 \\
\hline Household size & 5737 & 5.210 & $(1.424)$ & 1 & 16 \\
\hline Extended family & 5737 & 0.364 & $(0.481)$ & 0 & 1 \\
\hline Marital status (married) & 5737 & 0.998 & $(0.032)$ & 0 & 1 \\
\hline Muslims & 5737 & 0.798 & $(0.401)$ & 0 & 1 \\
\hline Catholics & 5737 & 0.082 & $(0.275)$ & 0 & 1 \\
\hline Orthodox & 5737 & 0.069 & $(0.254)$ & 0 & 1 \\
\hline Coastal region & 5737 & 0.262 & $(0.440)$ & 0 & 1 \\
\hline Mountain region & 5737 & 0.285 & $(0.451)$ & 0 & 1 \\
\hline Tirana region & 5737 & 0.164 & $(0.370)$ & 0 & 1 \\
\hline
\end{tabular}

Notes: The data used are the 2002 LSMS, the 2005 LSMS, the 2008-09 DHS and the 2012 LSMS 
Table 4: Fraction of Households that had Another Child by Parity and Sex Composition in Albania (2002- 2012)

\begin{tabular}{|c|c|c|c|c|}
\hline \multirow[t]{2}{*}{$\begin{array}{l}\text { Sex of the first child } \\
\text { in households with } \\
\text { one or more children }\end{array}$} & \multirow[t]{2}{*}{$\begin{array}{c}\text { Fraction } \\
\text { of the sample }\end{array}$} & \multicolumn{3}{|c|}{$\begin{array}{c}\text { Fraction that } \\
\text { had another child }\end{array}$} \\
\hline & & All & Urban & Rural \\
\hline \multicolumn{5}{|c|}{$\begin{array}{l}\text { Panel A: Mothers aged } 20 \text { to } 49 \text { years old with } \\
1 \text { or more children younger than } 18 \text { years old }\end{array}$} \\
\hline (1) one girl & 0.493 & $\begin{array}{l}0.809 \\
(0.005)\end{array}$ & $\begin{array}{c}0.781 \\
(0.008)\end{array}$ & $\begin{array}{c}0.841 \\
(0.007)\end{array}$ \\
\hline (2) one boy & 0.506 & $\begin{array}{c}0.764 \\
(0.006)\end{array}$ & $\begin{array}{c}0.752 \\
(0.008)\end{array}$ & $\begin{array}{c}0.777 \\
(0.008)\end{array}$ \\
\hline Difference (2) - (1) & $\begin{array}{c}0.012 \\
(0.010)\end{array}$ & $\begin{array}{c}-0.044 \\
(0.008)^{* * *}\end{array}$ & $\begin{array}{c}-0.028 \\
(0.011)^{* * *}\end{array}$ & $\begin{array}{c}-0.063 \\
(0.011)^{* * *}\end{array}$ \\
\hline Observations & 9509 & 9509 & 5049 & 4460 \\
\hline \multirow[t]{2}{*}{$\begin{array}{l}\text { Sex of first two childre } \\
\text { in households with } \\
\text { two or more children }\end{array}$} & $\begin{array}{l}\text { Fraction } \\
\text { of the sample }\end{array}$ & \multicolumn{3}{|c|}{$\begin{array}{l}\text { Fraction that } \\
\text { had another child }\end{array}$} \\
\hline & & All & Urban & Rural \\
\hline \multicolumn{5}{|c|}{$\begin{array}{l}\text { Panel B: Mothers aged } 20 \text { to } 49 \text { years old with } \\
2 \text { or more children younger than } 18 \text { years old }\end{array}$} \\
\hline one boy, one girl & 0.237 & $\begin{array}{c}0.352 \\
(0.011)\end{array}$ & $\begin{array}{c}0.265 \\
(0.014)\end{array}$ & $\begin{array}{c}0.441 \\
(0.016)\end{array}$ \\
\hline one girl, one boy & 0.260 & $\begin{array}{c}0.343 \\
(0.010)\end{array}$ & $\begin{array}{c}0.247 \\
(0.013)\end{array}$ & $\begin{array}{l}0.449 \\
(0.016)\end{array}$ \\
\hline two boys & 0.254 & $\begin{array}{c}0.364 \\
(0.011)\end{array}$ & $\begin{array}{c}0.277 \\
(0.014)\end{array}$ & $\begin{array}{l}0.458 \\
(0.016)\end{array}$ \\
\hline two girls & 0.247 & $\begin{array}{c}0.614 \\
(0.011)\end{array}$ & $\begin{array}{l}0.501 \\
(0.016)\end{array}$ & $\begin{array}{l}0.736 \\
(0.014)\end{array}$ \\
\hline (1) mixed combination & 0.497 & $\begin{array}{c}0.347 \\
(0.007)\end{array}$ & $\begin{array}{l}0.256 \\
(0.009)\end{array}$ & $\begin{array}{c}0.445 \\
(0.011)\end{array}$ \\
\hline (2) both same sex & 0.502 & $\begin{array}{l}0.487 \\
(0.008)\end{array}$ & $\begin{array}{l}0.387 \\
(0.011)\end{array}$ & $\begin{array}{l}0.595 \\
(0.011)\end{array}$ \\
\hline Difference (2) - (1) & $\begin{array}{c}0.005 \\
(0.011)\end{array}$ & $\begin{array}{c}0.140 \\
(0.011)^{* * *}\end{array}$ & $\begin{array}{c}0.131 \\
(0.014)^{* * *}\end{array}$ & $\begin{array}{c}0.150 \\
(0.016)^{* * *}\end{array}$ \\
\hline Observations & 7480 & 7480 & 3874 & 3606 \\
\hline
\end{tabular}

Notes: The data used are the 2002 LSMS, the 2005 LSMS, the 2008-09 DHS and the 2012 LSMS. * Indicates statistical significance at $10 \%$. ** Indicates statistical significance at $5 \%$. ${ }^{* * *}$ Indicates statistical significance at 1\%. Standard errors are in parenthesis. 
Table 5: Differences in Means for Demographic Characteristics by Sex Composition

\begin{tabular}{|c|c|c|c|c|c|c|}
\hline \multirow[b]{2}{*}{ Variables } & \multicolumn{3}{|c|}{ Mothers $(N=7480)$} & \multicolumn{3}{|c|}{ Fathers $(N=5496)$} \\
\hline & $\begin{array}{c}\text { Same-sex } \\
\text { (1) }\end{array}$ & $\begin{array}{c}\text { Two boys } \\
(2)\end{array}$ & $\begin{array}{c}\text { Two girls } \\
(3)\end{array}$ & $\begin{array}{c}\text { Same-sex } \\
(4)\end{array}$ & $\begin{array}{c}\text { Two boys } \\
(5)\end{array}$ & $\begin{array}{c}\text { Two girls } \\
(6)\end{array}$ \\
\hline Age & $\begin{array}{c}0.1252 \\
(0.1316)\end{array}$ & $\begin{array}{l}-0.1683 \\
(0.1510)\end{array}$ & $\begin{array}{c}0.3394 \\
(0.1523)^{* *}\end{array}$ & $\begin{array}{c}0.0045 \\
(0.1546)\end{array}$ & $\begin{array}{c}-0.3907 \\
(0.1769)^{* *}\end{array}$ & $\begin{array}{c}0.4085 \\
(0.1795)^{* *}\end{array}$ \\
\hline Age at first birth & $\begin{array}{l}-0.0160 \\
(0.0807)\end{array}$ & $\begin{array}{l}-0.0414 \\
(0.0926)\end{array}$ & $\begin{array}{c}0.0206 \\
(0.0934)\end{array}$ & $\begin{array}{l}-0.1199 \\
(0.1102)\end{array}$ & $\begin{array}{l}-0.2101 \\
(0.1362)\end{array}$ & $\begin{array}{c}0.0546 \\
(0.1281)\end{array}$ \\
\hline Years of education & $\begin{array}{l}-0.0186 \\
(0.0728)\end{array}$ & $\begin{array}{c}0.0020 \\
(0.0835)\end{array}$ & $\begin{array}{l}-0.0270 \\
(0.0843)\end{array}$ & $\begin{array}{c}0.0086 \\
(0.0920)\end{array}$ & $\begin{array}{l}-0.0392 \\
(0.1054)\end{array}$ & $\begin{array}{c}0.0520 \\
(0.1069)\end{array}$ \\
\hline Rural & $\begin{array}{l}-0.0014 \\
(0.0115)\end{array}$ & $\begin{array}{c}0.0011 \\
(0.0132)\end{array}$ & $\begin{array}{l}-0.0030 \\
(0.0133)\end{array}$ & $\begin{array}{c}0.0122 \\
(0.0131)\end{array}$ & $\begin{array}{c}0.0241 \\
(0.0150)\end{array}$ & $\begin{array}{l}-0.0083 \\
(0.0153)\end{array}$ \\
\hline Muslim & $\begin{array}{l}-0.0121 \\
(0.0089)\end{array}$ & $\begin{array}{l}-0.0109 \\
(0.0102)\end{array}$ & $\begin{array}{l}-0.0051 \\
(0.0103)\end{array}$ & $\begin{array}{l}-0.0082 \\
(0.0105)\end{array}$ & $\begin{array}{l}-0.0109 \\
(0.0121)\end{array}$ & $\begin{array}{c}0.0001 \\
(0.0123)\end{array}$ \\
\hline Catholic & $\begin{array}{c}0.0051 \\
(0.0063)\end{array}$ & $\begin{array}{c}0.0057 \\
(0.0072)\end{array}$ & $\begin{array}{c}0.0009 \\
(0.0073)\end{array}$ & $\begin{array}{c}0.0065 \\
(0.0072)\end{array}$ & $\begin{array}{c}0.0078 \\
(0.0083)\end{array}$ & $\begin{array}{c}0.0007 \\
(0.0084)\end{array}$ \\
\hline Orthodox & $\begin{array}{c}0.0020 \\
(0.0058)\end{array}$ & $\begin{array}{c}0.0085 \\
(0.0066)\end{array}$ & $\begin{array}{l}-0.0059 \\
(0.0067)\end{array}$ & $\begin{array}{c}0.0003 \\
(0.0067)\end{array}$ & $\begin{array}{c}0.0087 \\
(0.0076)\end{array}$ & $\begin{array}{c}0.0094 \\
(0.0078)\end{array}$ \\
\hline
\end{tabular}

Notes: Differences in means (mean of the relevant group minus mean of the rest of the population) and their standard errors (in parentheses). ${ }^{*}$ Indicates statistical significance at $10 \% . * *$ Indicates statistical significance at $5 \%$. *** Indicates statistical significance at $1 \%$. The sample of mothers consists of 7480 Albanian women aged 20 to 49 years old with two or more children aged 18 or younger. The sample for fathers consists of 5496 husbands of the married women with two or more children aged 18 or younger. The data used are the 2002 LSMS, the 2005 LSMS, the 2008-09 DHS and the 2012 LSMS 
Table 6: Differences in HH Budget Shares by Sex Child Composition in Albania (2002 - 2012)

\begin{tabular}{|c|c|c|c|c|}
\hline Variables & $\begin{array}{l}\text { Budget Share } \\
\text { (All) }\end{array}$ & Same-sex & Two boys & Two girls \\
\hline & $(1)$ & $(2)$ & (3) & $(4)$ \\
\hline HH Food Expenditure (S) & 0.548 & $\begin{array}{l}-0.001 \\
(0.004)\end{array}$ & $\begin{array}{c}-0.008^{*} \\
(0.004)\end{array}$ & $\begin{array}{c}0.006 \\
(0.004)\end{array}$ \\
\hline HH Health Expenditure (S) & 0.054 & $\begin{array}{l}-0.003 \\
(0.002)\end{array}$ & $\begin{array}{c}0.002 \\
(0.003)\end{array}$ & $\begin{array}{c}-0.007^{* *} \\
(0.003)\end{array}$ \\
\hline HH Clothing Expenditure (S) & 0.046 & $\begin{array}{c}0.001 \\
(0.001)\end{array}$ & $\begin{array}{l}-0.000 \\
(0.001)\end{array}$ & $\begin{array}{c}0.001 \\
(0.001)\end{array}$ \\
\hline Children's Education Expenditure (S) & 0.025 & $\begin{array}{l}-0.001 \\
(0.001)\end{array}$ & $\begin{array}{l}-0.002^{*} \\
(0.001)\end{array}$ & $\begin{array}{c}0.001 \\
(0.001)\end{array}$ \\
\hline Children's Clothing Expenditure (S) & 0.020 & $\begin{array}{l}0.001^{*} \\
(0.000)\end{array}$ & $\begin{array}{l}-0.000 \\
(0.000)\end{array}$ & $\begin{array}{c}0.002^{* * *} \\
(0.000)\end{array}$ \\
\hline Children's Education Expenditure (S.p.c) & 0.010 & $\begin{array}{c}-0.001^{* * *} * \\
(0.000)\end{array}$ & $\begin{array}{l}-0.000^{*} \\
(0.000)\end{array}$ & $\begin{array}{l}-0.001^{*} \\
(0.000)\end{array}$ \\
\hline Children's Clothing Expenditure (S.p.c) & 0.008 & $\begin{array}{l}-0.000 \\
(0.000)\end{array}$ & $\begin{array}{l}-0.000 \\
(0.000)\end{array}$ & $\begin{array}{l}-0.000 \\
(0.000)\end{array}$ \\
\hline Children's Clothes (S.p.c.) & 0.005 & $\begin{array}{l}-0.000 \\
(0.000)\end{array}$ & $\begin{array}{l}-0.000 \\
(0.000)\end{array}$ & $\begin{array}{l}-0.000 \\
(0.000)\end{array}$ \\
\hline Children's Footwear (S.p.c.) & 0.003 & $\begin{array}{l}-0.000 \\
(0.000)\end{array}$ & $\begin{array}{l}-0.000 \\
(0.000)\end{array}$ & $\begin{array}{l}-0.000 \\
(0.000)\end{array}$ \\
\hline
\end{tabular}

Notes: Differences in means (mean of the relevant group minus mean of the rest of the population) and their standard errors (in parentheses). * Indicates statistical significance at $10 \%$. ** Indicates statistical significance at 5\%.*** Indicates statistical significance at 1\%. The data used are the 2002 LSMS, the 2005 LSMS and the 2012 LSMS. The sample consists of 7480 Albanian mothers aged 20 to 49 years old with two or more children aged 18 or younger. (S) refers to the share of a particular expenditure over total expenditure, while (S.p.c) refers to the respective share divided by the number of children aged 18 or younger still living in the household. 
Table 7: First-Stage Specifications - Albania (2002 - 2012)

Instruments

Dependent Variable: Fertility (Number of children ever born)

(1)

(2)

(3)

(4)

$(5)$

(6)

$(7)$

Panel A: Mothers aged 20 to 49 years old with 2 or more children younger than 18 years old

\begin{tabular}{|c|c|c|c|c|c|c|c|}
\hline Boy first & - & - & - & $\begin{array}{c}-0.2461^{* * * *} \\
(0.0178)\end{array}$ & $\begin{array}{c}-0.2421^{* * *} \\
(0.0215)\end{array}$ & $\begin{array}{l}-0.0270 \\
(0.0201)\end{array}$ & $\begin{array}{l}-0.0283 \\
(0.0234)\end{array}$ \\
\hline Boy second & - & - & - & $\begin{array}{c}-0.2175^{* * *} \\
(0.0177)\end{array}$ & - & - & - \\
\hline Two girls & - & - & $\begin{array}{c}0.4723^{* * *} \\
(0.0254)\end{array}$ & - & 一 & $\begin{array}{c}0.4381^{* * *} \\
(0.0267)\end{array}$ & $\begin{array}{c}0.4381^{* * *} \\
(0.0267)\end{array}$ \\
\hline Two boys & - & $\begin{array}{c}-0.1621^{* * *} \\
(0.0209)\end{array}$ & - & - & $\begin{array}{c}0.0029 \\
(0.0226)\end{array}$ & - & $\begin{array}{c}0.0024 \\
(0.0226)\end{array}$ \\
\hline Same sex & $\begin{array}{c}0.2289^{* * * *} \\
(0.0192)\end{array}$ & - & - & $\begin{array}{c}0.2202^{* * *} \\
(0.0173)\end{array}$ & - & - & - \\
\hline R-squared & 0.1197 & 0.1090 & 0.1569 & 0.2982 & 0.2665 & 0.2982 & 0.2982 \\
\hline Observations & 7480 & 7480 & 7480 & 7404 & 7404 & 7404 & 7404 \\
\hline Survey FE & Yes & Yes & Yes & Yes & Yes & Yes & Yes \\
\hline District FE & Yes & Yes & Yes & Yes & Yes & Yes & Yes \\
\hline Controls & No & No & No & Yes & Yes & Yes & Yes \\
\hline
\end{tabular}

Panel B: Husband's of the married women with 2 or more children younger than 18 years old

\begin{tabular}{|c|c|c|c|c|c|c|c|}
\hline Boy first & - & - & - & $\begin{array}{c}-0.2393^{* * *} \\
(0.0204)\end{array}$ & $\begin{array}{c}-0.2311^{* * *} * \\
(0.0254)\end{array}$ & $\begin{array}{l}-0.0161 \\
(0.0233)\end{array}$ & $\begin{array}{l}-0.0153 \\
(0.0277)\end{array}$ \\
\hline Boy second & - & - & - & $\begin{array}{c}-0.2240^{* * *} * \\
(0.0205)\end{array}$ & - & - & - \\
\hline Two girls & - & - & $\begin{array}{c}0.4703^{* * *} \\
(0.0280)\end{array}$ & - & - & $\begin{array}{c}0.4465^{* * *} \\
(0.0304)\end{array}$ & $\begin{array}{c}0.4465^{* * *} * \\
(0.0304)\end{array}$ \\
\hline Two boys & - & $\begin{array}{c}-0.1615^{* * *} \\
(0.0235)\end{array}$ & - & - & $\begin{array}{c}-0.0003 \\
(0.0269)\end{array}$ & - & $\begin{array}{c}-0.0014 \\
(0.0269)\end{array}$ \\
\hline Same sex & $\begin{array}{c}0.2252^{* * *} \\
(0.0216)\end{array}$ & - & - & $\begin{array}{c}0.2225^{* * *} \\
(0.0201)\end{array}$ & - & - & - \\
\hline R-squared & 0.1160 & 0.1059 & 0.1530 & 0.2743 & 0.2415 & 0.2743 & 0.2743 \\
\hline Observations & 5737 & 5737 & 5737 & 5460 & 5460 & 5460 & 5460 \\
\hline Survey FE & Yes & Yes & Yes & Yes & Yes & Yes & Yes \\
\hline District FE & Yes & Yes & Yes & Yes & Yes & Yes & Yes \\
\hline Controls & No & No & No & Yes & Yes & Yes & Yes \\
\hline
\end{tabular}

Notes: Standard errors clustered at the PSU level are in parentheses. Other covariates in the models are the following: Age, Age Squared, Age at First birth, Years of Education and also indicators for Boy 1st and Boy 2nd. The variable Boy 2nd is excluded from models in columns (5), (6) and (7). Each model is estimated with survey and district fixed effects. ${ }^{*}$ Indicates statistical significance at $10 \%$. ${ }^{* *}$ Indicates statistical significance at $5 \%$. *** Indicates statistical significance at $1 \%$. 
Table 8: OLS and IV Estimates of Mother's Labor-Supply Models in Albania (2002 - 2012) (Mothers aged 20 to 49 years old with 2 or more children younger than 18 years old)

\begin{tabular}{|c|c|c|c|c|c|}
\hline Method & & & OLS & IV & IV \\
\hline $\begin{array}{l}\text { Instrument for Fertility: } \\
\text { (Number of children ever born) } \\
\text { Survey Fixed-Effects } \\
\text { District Fixed-Effects } \\
\text { Controls }\end{array}$ & & & $\begin{array}{l}- \\
\text { Yes } \\
\text { Yes } \\
\text { Yes }\end{array}$ & $\begin{array}{c}\text { Same-sex } \\
\text { Yes } \\
\text { Yes } \\
\text { Yes }\end{array}$ & $\begin{array}{c}\text { Two girls } \\
\text { Yes } \\
\text { Yes } \\
\text { Yes }\end{array}$ \\
\hline Dependent variable & Mean & Obs. & (1) & $(2)$ & $(3)$ \\
\hline \multicolumn{6}{|c|}{ Panel A: All databases (LSMS and DHS) } \\
\hline Worked in last 7 days & 0.445 & 7404 & $\begin{array}{l}-0.0063 \\
(0.0073)\end{array}$ & $\begin{array}{c}0.0474 \\
(0.0474)\end{array}$ & $\begin{array}{c}0.0360 \\
(0.0340)\end{array}$ \\
\hline Worked off-farm & 0.164 & 7404 & $\begin{array}{c}-0.0291^{* * *} \\
(0.0045)\end{array}$ & $\begin{array}{c}0.0052 \\
(0.0354)\end{array}$ & $\begin{array}{c}0.0503^{* *} \\
(0.0258)\end{array}$ \\
\hline Worked on-farm & 0.218 & 7404 & $\begin{array}{c}0.0347^{* * *} \\
(0.0066)\end{array}$ & $\begin{array}{c}0.0125 \\
(0.0396)\end{array}$ & $\begin{array}{c}-0.0019 \\
(0.0280)\end{array}$ \\
\hline Self-employed & 0.067 & 7404 & $\begin{array}{c}-0.0086^{* *} \\
(0.0037)\end{array}$ & $\begin{array}{c}0.0404 \\
(0.0270)\end{array}$ & $\begin{array}{c}-0.0107 \\
(0.0182)\end{array}$ \\
\hline \multicolumn{6}{|c|}{ Panel B: Only LSMS databases } \\
\hline Hours per week (total) & 16.69 & 4862 & $\begin{array}{c}-0.203 \\
(0.3867)\end{array}$ & $\begin{array}{c}4.697^{*} \\
(2.5509)\end{array}$ & $\begin{array}{c}4.409^{* *} \\
(1.8866)\end{array}$ \\
\hline Hours per week (off-farm) & 7.21 & 4862 & $\begin{array}{c}-1.429^{* * *} \\
(0.255)\end{array}$ & $\begin{array}{c}-0.078 \\
(1.902)\end{array}$ & $\begin{array}{l}2.683^{*} \\
(1.449)\end{array}$ \\
\hline Hours per week (on-farm) & 7.56 & 4862 & $\begin{array}{c}1.924^{* * *} \\
(0.321)\end{array}$ & $\begin{array}{c}2.303 \\
(1.779)\end{array}$ & $\begin{array}{c}1.570 \\
(1.332)\end{array}$ \\
\hline Hours per week (self) & 2.36 & 4862 & $\begin{array}{c}-0.470^{* *} \\
(0.181)\end{array}$ & $\begin{array}{c}2.841^{* *} \\
(1.444)\end{array}$ & $\begin{array}{c}0.225 \\
(1.024)\end{array}$ \\
\hline Second occupation & 0.014 & 4862 & $\begin{array}{c}0.004 \\
(0.002)\end{array}$ & $\begin{array}{c}0.010 \\
(0.014)\end{array}$ & $\begin{array}{c}0.002 \\
(0.011)\end{array}$ \\
\hline Monthly Labor Income & 50498.2 & 4862 & $\begin{array}{c}-6519.9^{* * *} \\
(1562.0)\end{array}$ & $\begin{array}{c}7404.5 \\
(12445.8)\end{array}$ & $\begin{array}{c}10966.55 \\
(9630.8)\end{array}$ \\
\hline
\end{tabular}

Notes: Standard errors clustered at the PSU level are in parentheses. All the models include the following covariates: Age, Age Squared, Age at First birth and Years of Education. IV Models in columns (2) and (3) also include indicators for Boy 1st and Boy 2nd. Each model is estimated with survey and district fixed effects. * Indicates statistical significance at $10 \%$. ** Indicates statistical significance at $5 \%$. *** Indicates statistical significance at $1 \%$. 
Table 9: OLS and IV Estimates of Father's Labor-Supply Models in Albania (2002 - 2012) (Husbands of married women aged 20 to 49 years old with 2 or more children younger than 18 years old)

\begin{tabular}{|c|c|c|c|c|c|}
\hline Method & & & OLS & IV & IV \\
\hline $\begin{array}{l}\text { Instrument for Fertility: } \\
\text { (Number of children ever born) } \\
\text { Survey Fixed-Effects } \\
\text { District Fixed-Effects } \\
\text { Controls } \\
\end{array}$ & & & $\begin{array}{l}- \\
\text { Yes } \\
\text { Yes } \\
\text { Yes }\end{array}$ & $\begin{array}{c}\text { Same-sex } \\
\text { Yes } \\
\text { Yes } \\
\text { Yes }\end{array}$ & $\begin{array}{c}\text { Two girls } \\
\text { Yes } \\
\text { Yes } \\
\text { Yes } \\
\end{array}$ \\
\hline Dependent variable & Mean & Obs. & (1) & $(2)$ & $(3)$ \\
\hline \multicolumn{6}{|c|}{ Panel A: All databases (LSMS and DHS) } \\
\hline Worked in last 7 days & 0.790 & 5460 & $\begin{array}{l}0.0124^{*} \\
(0.0067)\end{array}$ & $\begin{array}{c}0.0581 \\
(0.0445)\end{array}$ & $\begin{array}{c}0.0257 \\
(0.0314)\end{array}$ \\
\hline Worked off-farm & 0.394 & 5460 & $\begin{array}{c}-0.0234^{* * *} \\
(0.0080)\end{array}$ & $\begin{array}{c}0.0365 \\
(0.0537)\end{array}$ & $\begin{array}{c}0.0671^{*} \\
(0.0401)\end{array}$ \\
\hline Worked on-farm & 0.218 & 5460 & $\begin{array}{c}0.0347^{* * *} \\
(0.0066)\end{array}$ & $\begin{array}{c}0.0125 \\
(0.0396)\end{array}$ & $\begin{array}{l}-0.0019 \\
(0.0280)\end{array}$ \\
\hline Self-employed & 0.198 & 5460 & $\begin{array}{c}-0.0137^{* *} \\
(0.0063)\end{array}$ & $\begin{array}{c}0.0215 \\
(0.0437)\end{array}$ & $\begin{array}{c}-0.0072 \\
(0.0319)\end{array}$ \\
\hline \multicolumn{6}{|c|}{ Panel B: Only LSMS databases } \\
\hline Hours per week (total) & 34.39 & 4530 & $\begin{array}{c}0.1056 \\
(0.4501)\end{array}$ & $\begin{array}{l}-0.2895 \\
(2.8443)\end{array}$ & $\begin{array}{c}-1.1751 \\
(2.0713)\end{array}$ \\
\hline Hours per week (off-farm) & 18.60 & 4530 & $\begin{array}{c}-1.609^{* * *} \\
(0.426)\end{array}$ & $\begin{array}{l}-4.3926 \\
(2.8683)\end{array}$ & $\begin{array}{c}-0.8306 \\
(2.1766)\end{array}$ \\
\hline Hours per week (on-farm) & 9.15 & 4530 & $\begin{array}{c}2.744^{* * *} \\
(0.390)\end{array}$ & $\begin{array}{c}2.3598 \\
(2.2198)\end{array}$ & $\begin{array}{c}0.5399 \\
(1.6274)\end{array}$ \\
\hline Hours per week (self) & 7.65 & 4530 & $\begin{array}{c}-0.741^{* *} \\
(0.331)\end{array}$ & $\begin{array}{c}2.7154 \\
(2.3503)\end{array}$ & $\begin{array}{c}-0.0305 \\
(1.7875)\end{array}$ \\
\hline Second occupation & 0.058 & 4530 & $\begin{array}{l}0.008^{*} \\
(0.004)\end{array}$ & $\begin{array}{c}0.0321 \\
(0.0289)\end{array}$ & $\begin{array}{l}0.0406^{*} \\
(0.0230)\end{array}$ \\
\hline Monthly Labor Income & 193092.2 & 4530 & $\begin{array}{c}-11716.9^{* *} \\
(5189.7)\end{array}$ & $\begin{array}{c}-68559.5^{*} \\
(39727.2)\end{array}$ & $\begin{array}{c}-47677.86^{* *} \\
(24899.9)\end{array}$ \\
\hline
\end{tabular}

Notes: Standard errors clustered at the PSU level are in parentheses. All the models include the following covariates: Age, Age Squared, Age at First birth and Years of Education. IV Models in columns (2) and (3) also include indicators for Boy 1st and Boy 2nd. Each model is estimated with survey and district fixed effects. * Indicates statistical significance at $10 \%$. ** Indicates statistical significance at $5 \%$. *** Indicates statistical significance at $1 \%$. 
Table 10: OLS and IV Estimates of Parental Labor-Supply - Heterogeneity Analysis by Educational Attainment (Panel A: Mothers aged 20 to 49 years old with 2 or more children younger than 18 years old; and Panel B: their husbands)

\begin{tabular}{|c|c|c|c|c|c|c|c|c|c|c|}
\hline \multirow[b]{2}{*}{$\begin{array}{l}\text { Method } \\
\text { Instrument for Fertility: }\end{array}$} & \multicolumn{5}{|c|}{$\begin{array}{l}\text { Primary Educ. Level } \\
\text { ( } \leq 8 \text { years of schooling) }\end{array}$} & \multicolumn{5}{|c|}{$\begin{array}{c}\text { Above Primary Educ. Level } \\
\text { (>8 years of schooling })\end{array}$} \\
\hline & & & OLS & $\begin{array}{c}\text { IV } \\
\text { Same-sex }\end{array}$ & $\begin{array}{c}\text { IV } \\
\text { Two girls }\end{array}$ & & & OLS & $\begin{array}{c}\text { IV } \\
\text { Same-sex }\end{array}$ & $\begin{array}{c}\text { IV } \\
\text { Two girls }\end{array}$ \\
\hline Survey Fixed-Effects & & & Yes & Yes & Yes & & & Yes & Yes & Yes \\
\hline District Fixed-Effects & & & Yes & Yes & Yes & & & Yes & Yes & Yes \\
\hline Controls & & & Yes & Yes & Yes & & & Yes & Yes & Yes \\
\hline Dependent variable & Mean & Obs. & (1) & (2) & (3) & Mean & Obs. & (4) & (5) & (6) \\
\hline
\end{tabular}

\begin{tabular}{|c|c|c|c|c|c|c|c|c|c|c|}
\hline Worked off-farm & 0.054 & 3900 & $\begin{array}{c}-0.019 * * * \\
(0.004)\end{array}$ & $\begin{array}{c}0.014 \\
(0.028)\end{array}$ & $\begin{array}{c}0.033 \\
(0.021)\end{array}$ & 0.286 & 3504 & $\begin{array}{c}-0.059^{* * *} \\
(0.011)\end{array}$ & $\begin{array}{l}-0.023 \\
(0.080)\end{array}$ & $\begin{array}{c}0.073 \\
(0.060)\end{array}$ \\
\hline Hours per week & 14.56 & 2578 & $\begin{array}{c}0.140 \\
(0.461)\end{array}$ & $\begin{array}{l}5.523^{*} \\
(3.012)\end{array}$ & $\begin{array}{l}4.092^{*} \\
(2.185)\end{array}$ & 19.09 & 2284 & $\begin{array}{c}-1.755^{* *} \\
(0.728)\end{array}$ & $\begin{array}{c}3.398 \\
(4.660)\end{array}$ & $\begin{array}{c}4.514 \\
(3.632)\end{array}$ \\
\hline \multicolumn{11}{|c|}{ Panel B: Fathers } \\
\hline Worked off-farm & 0.283 & 2420 & $\begin{array}{c}-0.024^{* *} \\
(0.010)\end{array}$ & $\begin{array}{c}0.030 \\
(0.077)\end{array}$ & $\begin{array}{c}0.060 \\
(0.049)\end{array}$ & 0.482 & 3040 & $\begin{array}{l}-0.017 \\
(0.013)\end{array}$ & $\begin{array}{c}0.034 \\
(0.077)\end{array}$ & $\begin{array}{c}0.068 \\
(0.063)\end{array}$ \\
\hline Second occupation & 0.054 & 2048 & $\begin{array}{l}-0.000 \\
(0.006)\end{array}$ & $\begin{array}{c}0.055 \\
(0.040)\end{array}$ & $\begin{array}{l}0.052^{*} \\
(0.028)\end{array}$ & 0.062 & 2482 & $\begin{array}{c}0.018^{* *} \\
(0.007)\end{array}$ & $\begin{array}{c}0.008 \\
(0.044)\end{array}$ & $\begin{array}{c}0.026 \\
(0.037)\end{array}$ \\
\hline
\end{tabular}

Notes: Standard errors clustered at the PSU level are in parentheses. All the models include the following covariates: Age, Age Squared, Age at First birth and Years of Education. IV Models in columns (2) and (3) also include indicators for Boy 1st and Boy 2nd. Each model is estimated with survey and district fixed effects. $*$ Indicates statistical significance at $10 \%$. ** Indicates statistical significance at $5 \%$. *** Indicates statistical significance at $1 \%$. 
Table 11: OLS and IV Estimates of Parental Labor-Supply - Heterogeneity Analysis by Birth Cohort (Panel A: Mothers aged 20 to 49 years old with 2 or more children younger than 18 years old; and Panel B: their husbands)

\begin{tabular}{|c|c|c|c|c|c|c|c|c|c|c|}
\hline \multirow[b]{2}{*}{$\begin{array}{l}\text { Method } \\
\text { Instrument for Fertility: }\end{array}$} & \multicolumn{5}{|c|}{ Younger Parent } & \multicolumn{5}{|c|}{ Older Parent } \\
\hline & & & $\begin{array}{c}\text { OLS } \\
-\end{array}$ & $\begin{array}{c}\text { IV } \\
\text { Same-sex }\end{array}$ & $\begin{array}{c}\text { IV } \\
\text { Two girls }\end{array}$ & & & $\begin{array}{c}\text { OLS } \\
-\end{array}$ & $\begin{array}{c}\text { IV } \\
\text { Same-sex }\end{array}$ & $\begin{array}{c}\text { IV } \\
\text { Two girls }\end{array}$ \\
\hline Survey Fixed-Effects & & & Yes & Yes & Yes & & & Yes & Yes & Yes \\
\hline District Fixed-Effects & & & Yes & Yes & Yes & & & Yes & Yes & Yes \\
\hline Controls & & & Yes & Yes & Yes & & & Yes & Yes & Yes \\
\hline Dependent variable & Mean & Obs. & (1) & (2) & $(3)$ & Mean & Obs. & (4) & $(5)$ & (6) \\
\hline
\end{tabular}

Panel A.1. Mothers born after 1972

\begin{tabular}{|c|c|c|c|c|c|c|c|c|c|c|}
\hline Worked off-farm & 0.111 & 3253 & $\begin{array}{c}-0.024^{* * *} \\
(0.007)\end{array}$ & $\begin{array}{c}0.032 \\
(0.056)\end{array}$ & $\begin{array}{c}0.058 \\
(0.043)\end{array}$ & 0.205 & 4151 & $\begin{array}{c}-0.031^{* * *} \\
(0.006)\end{array}$ & $\begin{array}{l}-0.011 \\
(0.045)\end{array}$ & $\begin{array}{c}0.048 \\
(0.032)\end{array}$ \\
\hline \multirow[t]{2}{*}{ Hours per week } & 11.95 & 2019 & $\begin{array}{l}-1.002 \\
(0.687)\end{array}$ & $\begin{array}{c}14.292^{* * *} \\
(5.066)\end{array}$ & $\begin{array}{c}10.584^{* * *} \\
(3.723)\end{array}$ & 20.05 & 2843 & $\begin{array}{l}-0.007 \\
(0.484)\end{array}$ & $\begin{array}{l}-0.010 \\
(3.043)\end{array}$ & $\begin{array}{c}1.599 \\
(2.180)\end{array}$ \\
\hline & \multicolumn{5}{|c|}{ Panel B.1. Fathers born after 1966} & \multicolumn{2}{|c|}{ Panel B.2. } & \multicolumn{3}{|c|}{ Fathers born before 1966 (incl.) } \\
\hline Worked off-farm & 0.349 & 2719 & $\begin{array}{l}-0.009 \\
(0.013)\end{array}$ & $\begin{array}{c}0.083 \\
(0.096)\end{array}$ & $\begin{array}{c}0.070 \\
(0.069)\end{array}$ & 0.439 & 2741 & $\begin{array}{c}-0.036^{* * *} \\
(0.010)\end{array}$ & $\begin{array}{c}0.008 \\
(0.064)\end{array}$ & $\begin{array}{c}0.063 \\
(0.050)\end{array}$ \\
\hline Second occupation & 0.056 & 2194 & $\begin{array}{c}0.009 \\
(0.007)\end{array}$ & $\begin{array}{c}0.095 \\
(0.058)\end{array}$ & $\begin{array}{l}0.079^{*} \\
(0.042)\end{array}$ & 0.061 & 2336 & $\begin{array}{c}0.008 \\
(0.005)\end{array}$ & $\begin{array}{l}-0.005 \\
(0.032)\end{array}$ & $\begin{array}{c}0.015 \\
(0.027)\end{array}$ \\
\hline
\end{tabular}

Notes: Standard errors clustered at the PSU level are in parentheses. All the models include the following covariates: Age, Age Squared, Age at First birth and Years of Education. IV Models in columns (2) and (3) also include indicators for Boy 1st and Boy 2nd. Each model is estimated with survey and district fixed effects. $*$ Indicates statistical significance at $10 \%$. ** Indicates statistical significance at $5 \%$. *** Indicates statistical significance at $1 \%$. 
Table 12: OLS and IV Estimates of Parental Labor-Supply - Heterogeneity Analysis by Family Structure (Panel A: Mothers aged 20 to 49 years old with 2 or more children younger than 18 years old; and Panel B: their husbands)

\begin{tabular}{|c|c|c|c|c|c|c|c|c|c|c|}
\hline \multirow[b]{2}{*}{$\begin{array}{l}\text { Method } \\
\text { Instrument for Fertility: }\end{array}$} & \multicolumn{5}{|c|}{ Extended Family } & \multicolumn{5}{|c|}{ Non-Extended Family } \\
\hline & & & OLS & $\begin{array}{c}\text { IV } \\
\text { Same-sex }\end{array}$ & $\begin{array}{c}\text { IV } \\
\text { Two girls }\end{array}$ & & & OLS & $\begin{array}{c}\text { IV } \\
\text { Same-sex }\end{array}$ & $\begin{array}{c}\text { IV } \\
\text { Two girls }\end{array}$ \\
\hline Survey Fixed-Effects & & & Yes & Yes & Yes & & & Yes & Yes & Yes \\
\hline District Fixed-Effects & & & Yes & Yes & Yes & & & Yes & Yes & Yes \\
\hline Controls & & & Yes & Yes & Yes & & & Yes & Yes & Yes \\
\hline Dependent variable & Mean & Obs. & (1) & $(2)$ & $(3)$ & Mean & Obs. & $(4)$ & $(5)$ & $(6)$ \\
\hline
\end{tabular}

\begin{tabular}{|c|c|c|c|c|c|c|c|c|c|c|}
\hline Worked off-farm & 0.162 & 2804 & $\begin{array}{c}-0.037^{* * *} \\
(0.008)\end{array}$ & $\begin{array}{c}0.020 \\
(0.060)\end{array}$ & $\begin{array}{l}0.077^{*} \\
(0.046)\end{array}$ & 0.165 & 4600 & $\begin{array}{c}-0.025^{* * *} \\
(0.006)\end{array}$ & $\begin{array}{l}-0.001 \\
(0.044)\end{array}$ & $\begin{array}{c}0.038 \\
(0.032)\end{array}$ \\
\hline Hours per week & 17.37 & 1729 & $\begin{array}{l}-0.663 \\
(0.715)\end{array}$ & $\begin{array}{l}7.532^{*} \\
(4.303)\end{array}$ & $\begin{array}{l}6.982^{*} \\
(3.564)\end{array}$ & 16.31 & 3133 & $\begin{array}{l}-0.043 \\
(0.462)\end{array}$ & $\begin{array}{c}3.620 \\
(3.294)\end{array}$ & $\begin{array}{c}3.536 \\
(3.278)\end{array}$ \\
\hline \multicolumn{11}{|c|}{ Panel B: Fathers } \\
\hline Worked off-farm & 0.359 & 1967 & $\begin{array}{l}-0.013 \\
(0.015)\end{array}$ & $\begin{array}{c}0.107 \\
(0.091)\end{array}$ & $\begin{array}{c}0.061 \\
(0.071)\end{array}$ & 0.414 & 3493 & $\begin{array}{c}-0.027^{* * *} \\
(0.009)\end{array}$ & $\begin{array}{l}-0.005 \\
(0.071)\end{array}$ & $\begin{array}{c}0.072 \\
(0.049)\end{array}$ \\
\hline Second occupation & 0.060 & 1607 & $\begin{array}{c}0.009 \\
(0.007)\end{array}$ & $\begin{array}{c}0.044 \\
(0.048)\end{array}$ & $\begin{array}{c}-0.012 \\
(0.040)\end{array}$ & 0.057 & 2923 & $\begin{array}{l}0.008 \\
(0.005)\end{array}$ & $\begin{array}{c}0.027 \\
(0.038)\end{array}$ & $\begin{array}{c}0.071^{* *} \\
(0.028)\end{array}$ \\
\hline
\end{tabular}

Notes: Standard errors clustered at the PSU level are in parentheses. All the models include the following covariates: Age, Age Squared, Age at First birth and Years of Education. IV Models in columns (2) and (3) also include indicators for Boy 1st and Boy 2nd. Each model is estimated with survey and district fixed effects. ${ }^{*}$ Indicates statistical significance at $10 \%$. ${ }^{* *}$ Indicates statistical significance at $5 \% .{ }^{* * *}$ Indicates statistical significance at $1 \%$. 
Table 13: IV Estimates of the Effect of Fertility on Family Spending per-capita - Heterogeneity Analysis by Expenditure Quintiles and Family Structure - Albania (2002 - 2012)

\begin{tabular}{|c|c|c|c|c|c|c|}
\hline \multirow[b]{2}{*}{ Variables } & \multirow[b]{2}{*}{ All } & \multicolumn{5}{|c|}{ Expenditure Quintiles } \\
\hline & & $\begin{array}{c}\text { Q1 } \\
\text { (Poorest) }\end{array}$ & $\begin{array}{c}\text { Q2 } \\
\text { (Poorer) }\end{array}$ & $\begin{array}{c}\text { Q3 } \\
\text { (Middle) }\end{array}$ & $\begin{array}{c}\text { Q4 } \\
\text { (Richer) }\end{array}$ & $\begin{array}{c}\text { Q5 } \\
\text { (Richest) }\end{array}$ \\
\hline Mother's age & 35.04 & 34.38 & 34.82 & 35.03 & 35.35 & 35.91 \\
\hline Mother's age at 1 st birth & 23.22 & 23.06 & 23.02 & 23.11 & 23.33 & 23.70 \\
\hline Father's age & 39.91 & 38.77 & 39.85 & 39.98 & 40.36 & 40.95 \\
\hline Father's age at 1st birth & 28.33 & 27.86 & 28.14 & 28.23 & 28.60 & 29.01 \\
\hline$\%$ Rural & 0.482 & 0.699 & 0.656 & 0.492 & 0.309 & 0.209 \\
\hline$\%$ Third child & 0.418 & 0.488 & 0.445 & 0.430 & 0.384 & 0.310 \\
\hline$\%$ Extended Family & 0.381 & 0.313 & 0.384 & 0.386 & 0.394 & 0.451 \\
\hline
\end{tabular}

Dependent variable: Ln (Per-capita Expenditure)

Fertility

$\begin{array}{lcccccc}\text { IV (same sex) } & -0.0890 & 0.1579 & -0.0252 & -0.1985^{* * *} & -0.0309 & -0.2110 \\ & (0.0826) & (0.1811) & (0.1036) & (0.0632) & (0.1505) & (0.1321) \\ \text { IV (two girls) } & -0.1563^{* *} & -0.0948 & -0.0979 & -0.2180^{* * *} & -0.1487 & -0.2967^{* *} \\ & (0.0674) & (0.1184) & (0.0683) & (0.0585) & (0.0950) & (0.1162) \\ \text { Observations } & 1699 & 248 & 340 & 401 & 450 & 260\end{array}$

Fertility

Panel B: Non-Extended Family

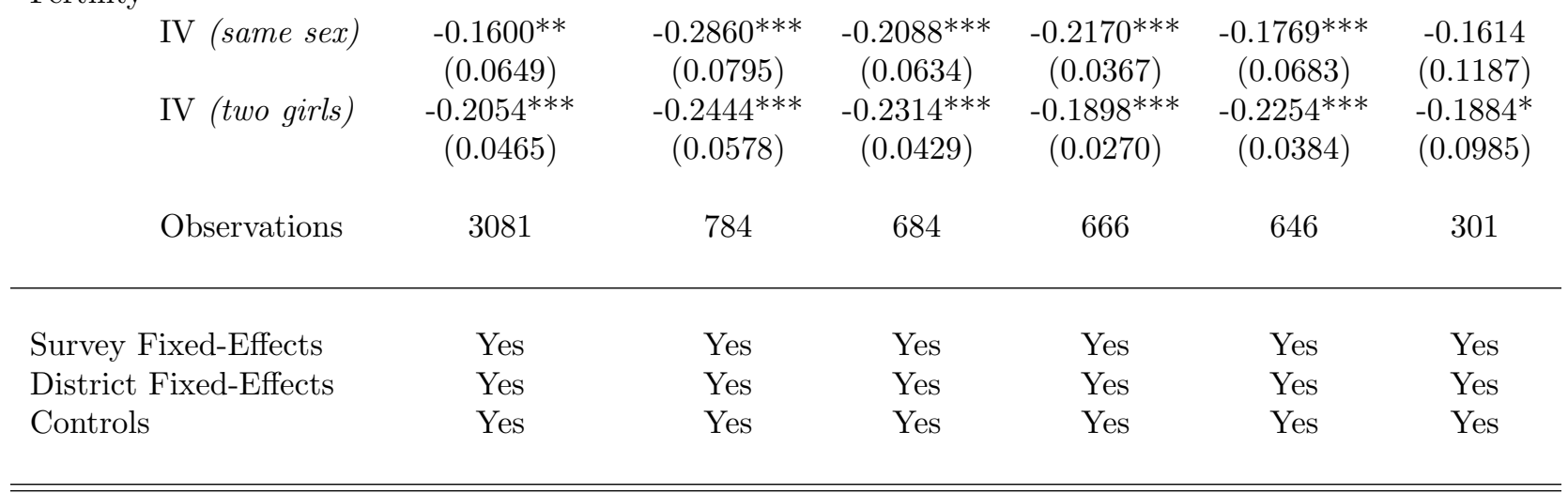

Notes: Standard errors clustered at the PSU level are in parentheses. The IV models include the following covariates: Age, Age Squared, Age at First birth, Years of Education, Boy1st and Boy 2nd. Boy 2nd is excluded from the IV specification that uses two girls as an instrument. Each model is estimated with survey and district fixed effects. ${ }^{*}$ Indicates statistical significance at $10 \%$. ${ }^{* *}$ Indicates statistical significance at $5 \% .{ }^{* * *}$ Indicates statistical significance at $1 \%$. 
Figure 1: Evolution of the Total Fertility Rate in Albania (1960 - 2012)

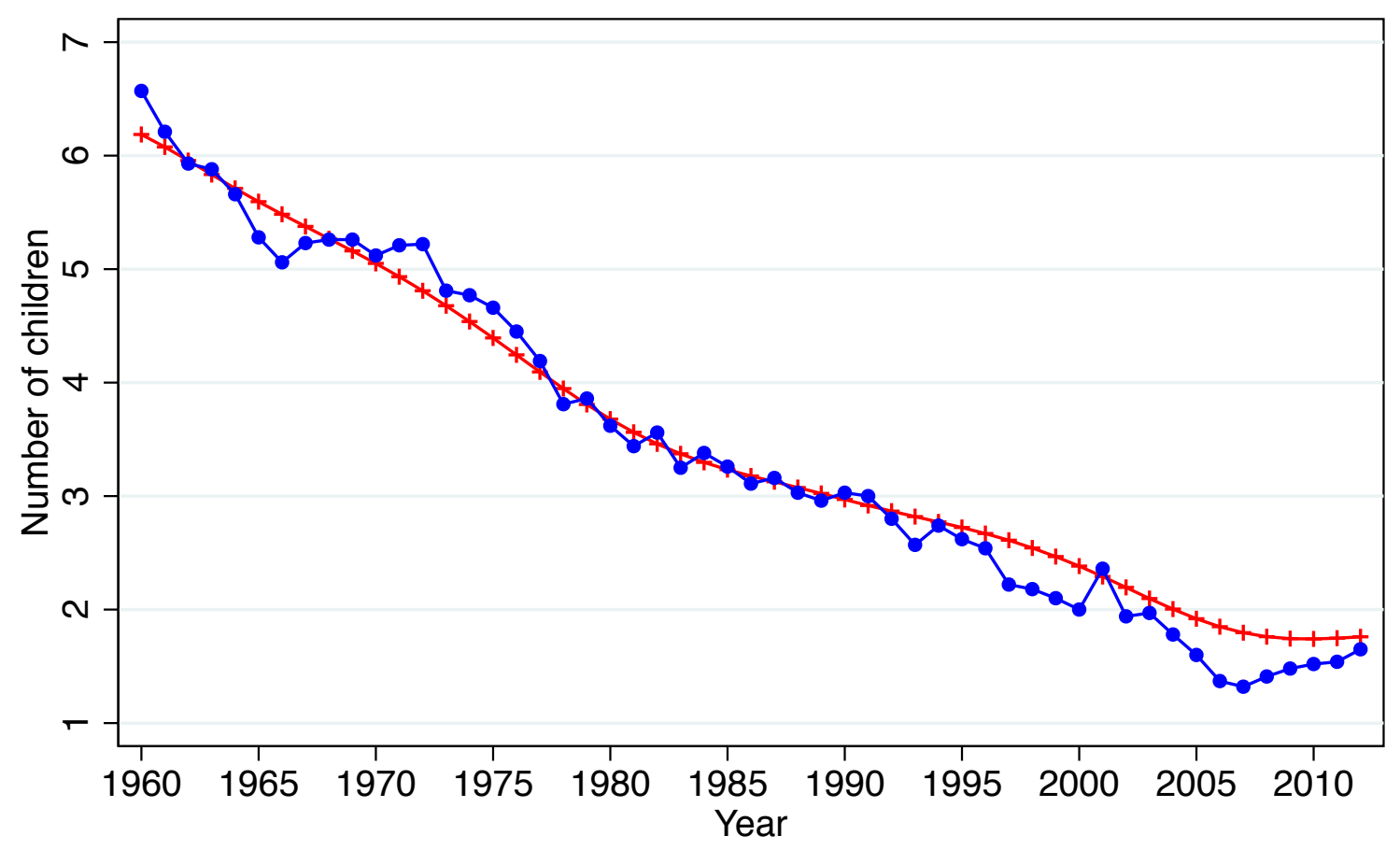

— Total Fertility Rate (Source: World Development Indicators)

$\longrightarrow$ Total Fertility Rate (Source: INSTAT)

Notes: According to Gjonça et al (2008), the total fertility rate rose during the 1950 s reaching a peak of almost 7 children per woman by 1960. This was followed in the 1970s by a steady decline, with a total fertility rate of less than 4 in 1980 and just over 3 children per woman in 1990. The 1990s saw a continuing reduction which reached the replacement level of 2.2 children per woman in 2002, which at the same time was the highest fertility rate in Europe. During the 2000s the total fertility rate has decreased even further reaching a level of 1.65 children per women in 2012, which currently characterizes Albania as a country with a very low fertility rate. 
Figure 2: Labor-Force Pariticpation and Total Fertility Rate - Albania (1990 - 2012)

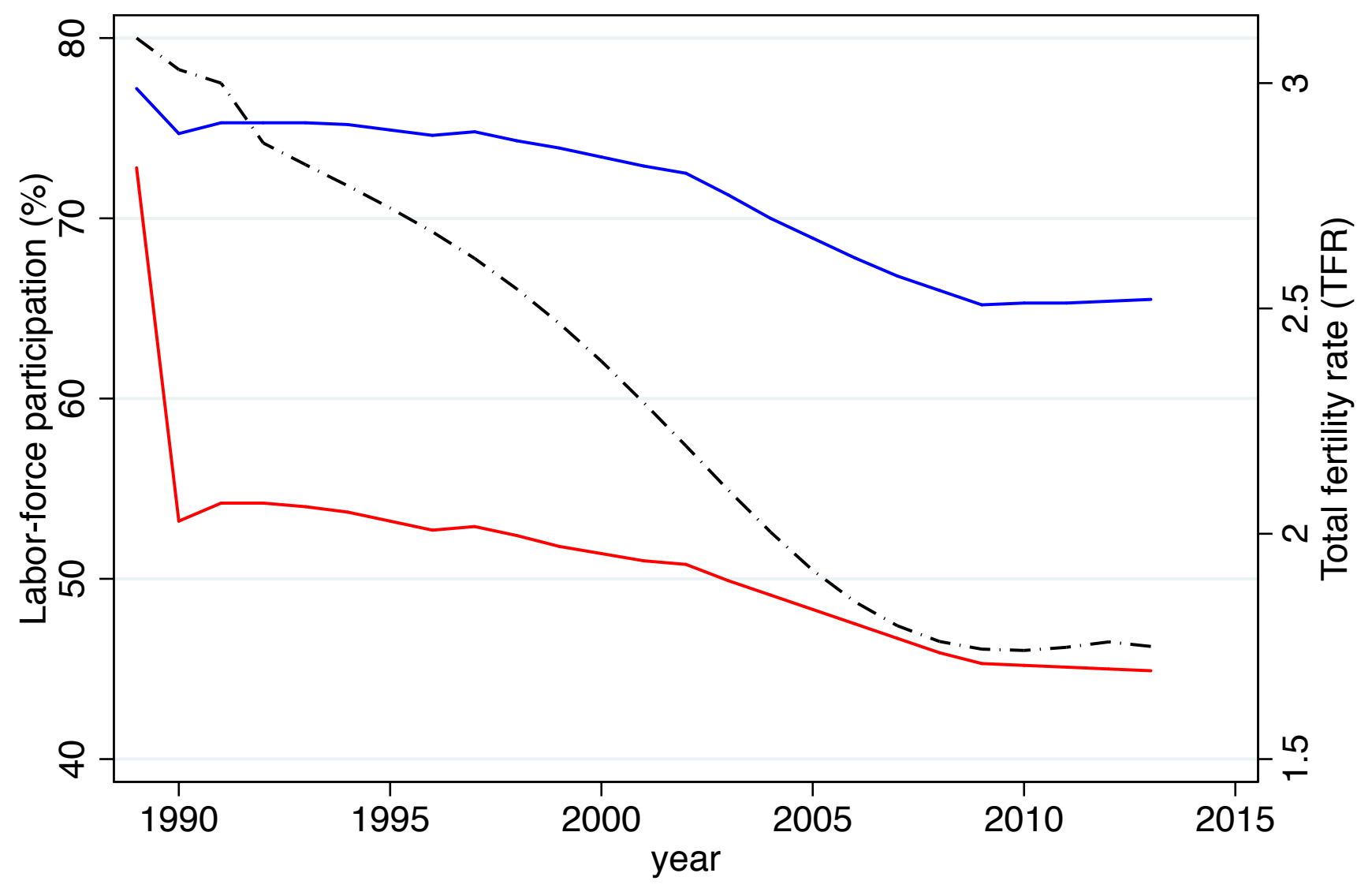

Male (ages 15+)

Female (ages 15+) $\quad--\cdot-\cdot-$ TFR 
Figure 3: Pre-school in Albania (1990 - 2012)

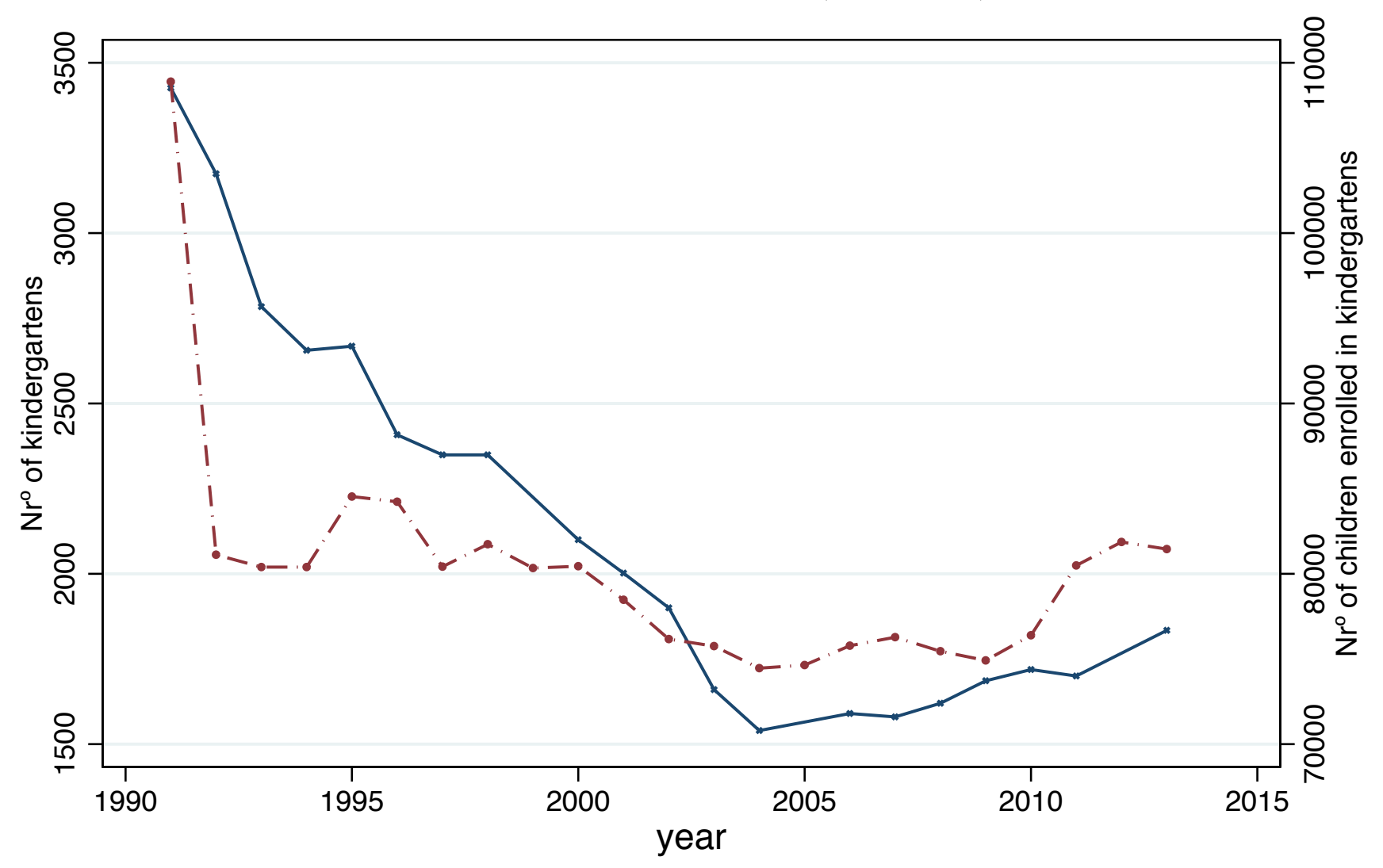

Number of kindergartens

Numer of children enrolled in kindergartens

Source: Albanian Institute of Statistics (INSTAT) and Ministry of Education and Sports (MAS)

Notes: Data for public and private kindergartens in total, since 2006-07 year school. 
Figure 4: Graphical Version of Fraction of Households that had Another Child by Parity and Sex Composition - Decomposed by Survey

(Mothers 20 to 49 years old with at least 2 children younger than 18 years old)
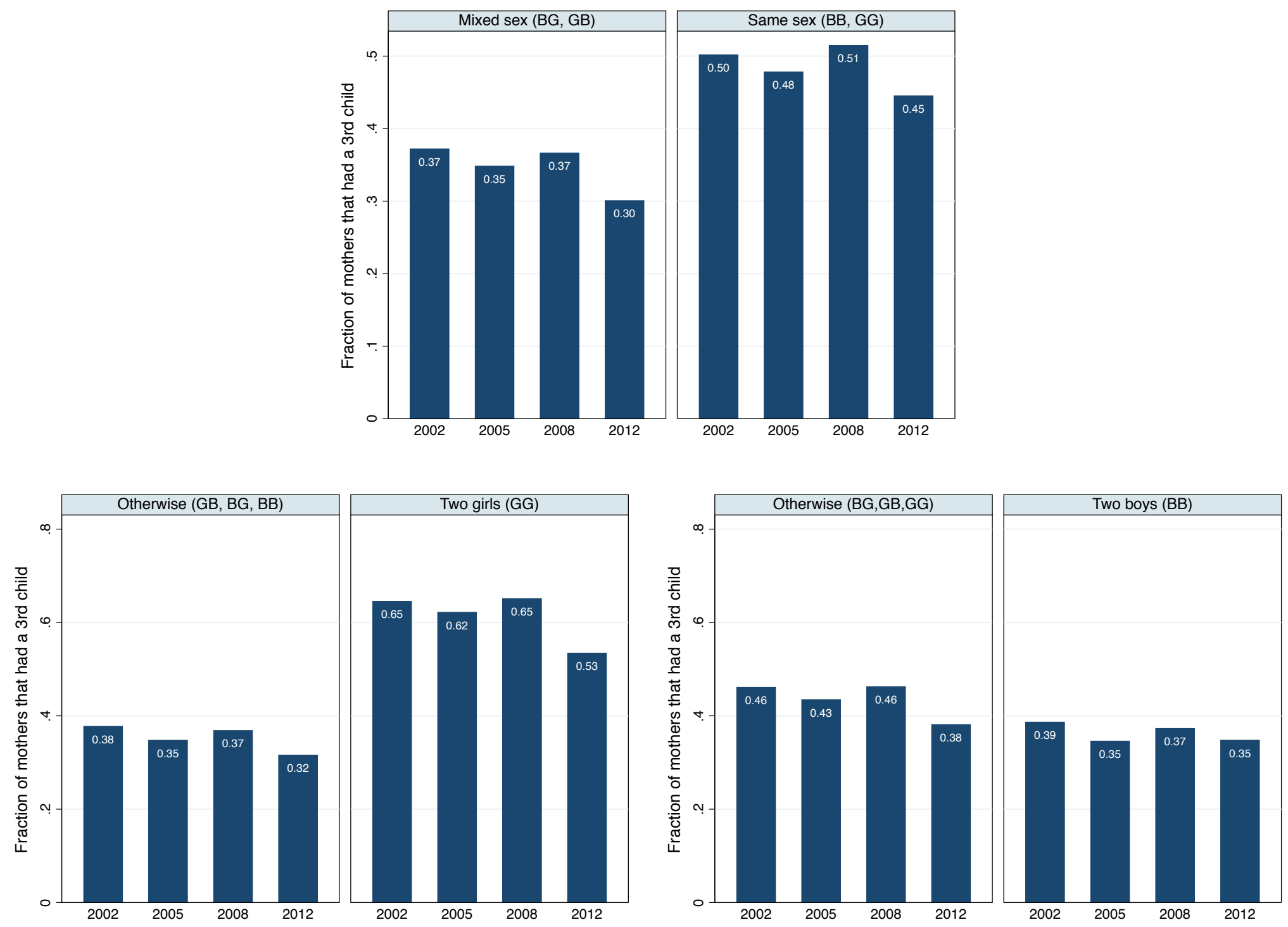
Figure 5: Proportion of parents in extended families living with their married son by their son's birth order

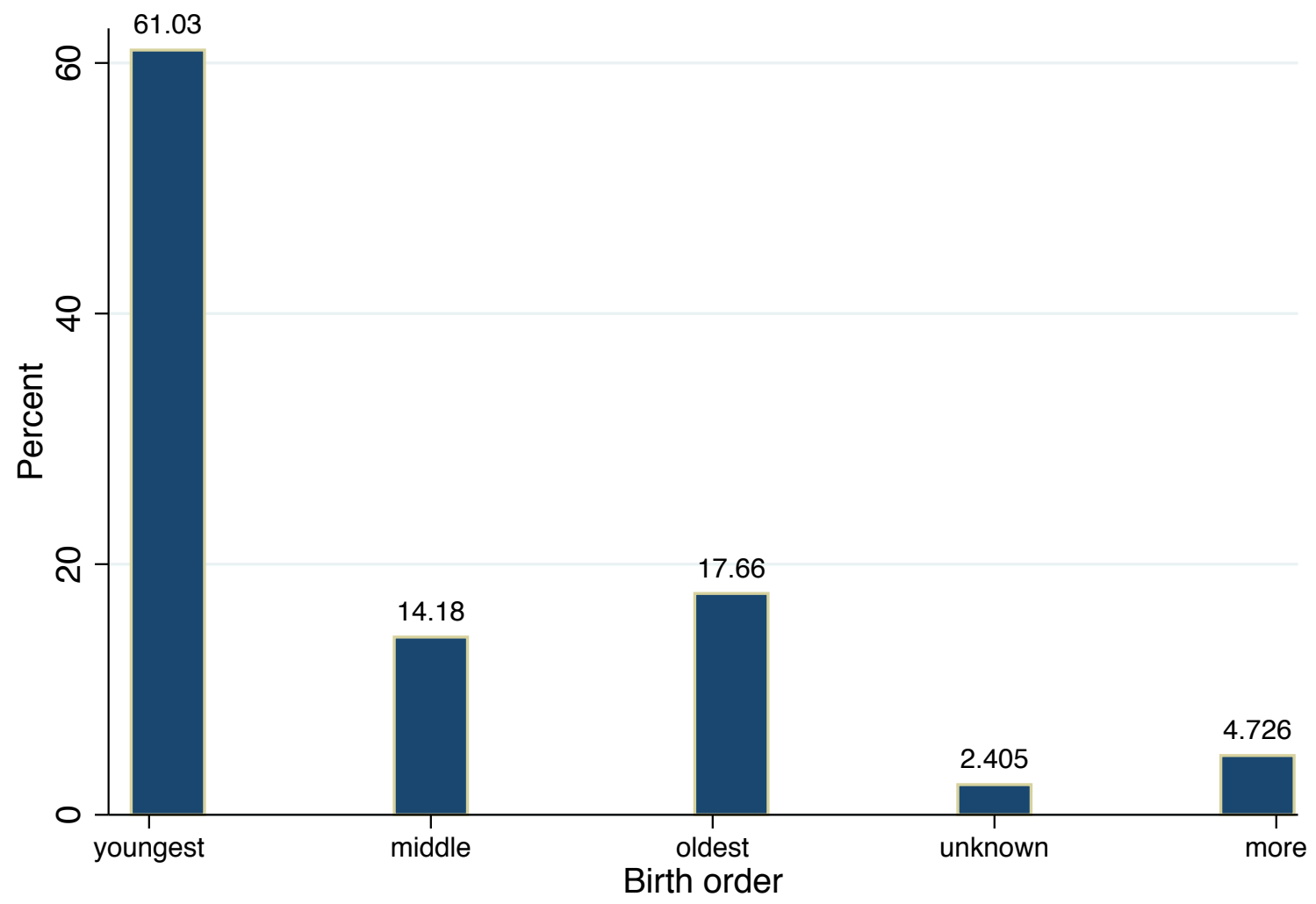

Source: 2002 Albania LSMS 
APPENDIX 


\section{A Appendix 1 - Data sources and data construction}

The 2002, 2005 and 2012 LSMS were undertaken by the Albanian National Institute of Statistics (INSTAT) with the technical assistance of the World Bank; the 2008-09 DHS was also conducted by the INSTAT but also by the Institute of Public Health (IPH). All these databases are nationally representative surveys for the whole country, as well as at regional and at the urban/rural level. Each survey contains a wide range of information on individuals demographic and socioeconomic characteristics (i.e. fertility, health, employment, migration and education among many others). The LSMS surveys also comprise a detailed expenditure section which is used in this study to obtain figures on clothing and schooling expenditures on children. The DHS is especially characterized for having broader information about health. In each one of the databases, the country was stratified into four regions (strata), Tirana, Coastal, Central and Mountain. All the surveyed individuals belong to the 36 districts in the country, with all regions nearly equally represented. They are also based on a two-stage sampling cluster design.

The 2002 LSMS is the first survey of this type conducted in Albania. This survey includes 3,600 households, from which 8,395 are men and 8,126 are women. Three years later, the same survey was redone but unfortunately the same households were not followed in time in order to form a panel. ${ }^{25}$ The 2005 LSMS covers 3,638 households, from which 8,713 are men and 8,589 are women. The 2008-09 DHS comprises a total of 7,999 households, from which 7,584 are women and 3,013 are men. And lastly, the 2012 LSMS contains in total 6,671 household observations, from where 12,747 correspond to men and 12,588 correspond to women. The respective original individual observations for each survey are reported in Table A.1 below. ${ }^{26}$

These surveys interviewed both women and men with respect to their fertility decisions, thereby permitting the unique opportunity to incorporate information in my study regarding the fertility history of each household. In the 2008-09 DHS, all the children ever born are already matched to each one of the mothers and fathers they correspond to, which makes the DHS a perfect database for studying the fertility history of the parents. In addition, their gender, age, date of birth, month of birth, year of birth and birth order among other characteristics

\footnotetext{
${ }^{25}$ The data from the 2002 LSMS has been used to construct a panel survey with two additional waves, one in 2003 and another one in 2004. The problem with this panel survey is that the questionnaire was readministered only to a sub-sample of the 2002 LSMS households, which reduces a lot the sample size in order to allow for the adopted empirical strategy in this study.

${ }^{26}$ For further information on the Albanian LSMS surveys, see the documentation of the World Bank available online: http://www.worldbank.org/lsms/index.htm.
} 
are very well indicated. In contrast, in the LSMS surveys, the fertility history information is not as clearly presented as in the DHS, which means that the children are not already linked to their corresponding parents. However, the advantage of the LSMS surveys is that they provide a direct mother and father identifier code, which is used to link the children to their corresponding parents.

In addition, the LSMSs databases contain very detailed information on the family structure of each one of the households, including information about the children no longer living in the household, which makes possible the construction of the entire fertility history of each parent. This means that, in the LSMS surveys, it is possible to identify which one of the individuals is the head of the household, which is the spouse, which are the children and also which are the other members of the family such as grandparents, sisters, brothers, uncles, aunts etc. Apart from this, it is possible to identify the age and gender of each one of the household individuals, which is very useful to construct the number of children per parent and also the birth order of each one of them. Therefore, for the LSMSs databases, I identified one by one all the children corresponding to each mother and father, their gender, age, year of birth and birth order with respect to their siblings. Then by reshaping each database, I could match all the children to their corresponding parents within households by using the mother and father identifier code and at the same time I could order the children from youngest to eldest by birth order. As a crosscheck, I also attached individuals in a household labeled as "child" in the primary relationship code to a female householder or the spouse of a male householder. In households with multiple families, detailed relationship codes as well as subfamily identifiers were used to pair children with mothers.

On the other hand, the Household Roaster Module of the LSMSs databases contains detailed information on each one of the members who were living in the household at the time of the survey but it does not contain information on other members such as sons or daughters who had already left the household. Therefore, in order to construct the entire fertility history of each woman I had to use information about the sons and daughters living away, which is available in the Migration Module of the LSMSs databases.

However, a small concern about the Migration Module is that this information might be subject to measurement errors. More precisely, the major concern comes from the plausible underreporting of daughters. The first reason behind this concern might be to the fact that 
Albanian parents expect at least one of their sons to take care of them at old age, while the rest of the children especially girls leave the household. Albanian tradition mandates that it is the role of the youngest son to take care of the parents in their later years. Therefore, it could be that there are many households that report only sons because it has been impossible to track the rest of the siblings. The second reason could be to pre-natal sex selection. In some developing countries including Albania, the presence of strong son preference could affect the sex composition of children, either through stopping rules or selective abortion. However, by restricting the sample of women to mothers with at least two children whose oldest child is at most 18 years old at the time of the survey, I rule out these two concerns and I find that the fraction of households that had a boy or a girl as a first child is quite balanced for each of the four databases (see Table A-2). Hence, due to these reasons and also because it is more relevant to study the effect of fertility on labor supply for the parents whose children still live in the household, I restrict my sample to mothers aged 20 to 49 with at least two children, whose oldest child was at most 18 years old at the time of the survey and for the case of the fathers I restrict my sample to the husbands of the married women. 
Table A-1: Sample Sizes: LSMS and DHS - Albania (2002-2012)

\begin{tabular}{|c|c|c|c|c|c|c|c|}
\hline Survey & Households & Women & Men & Individuals & $\begin{array}{c}\text { Women } \\
20 \leq \text { age } \leq 49\end{array}$ & $\begin{array}{c}\text { Women } \\
\text { with }+2 \text { children } \\
\text { below } 18 \text { y.o. } \\
20 \leq \text { age } \leq 49\end{array}$ & $\begin{array}{c}\text { Husbands of the } \\
\text { married women } \\
20 \leq \text { age } \leq 49 *\end{array}$ \\
\hline
\end{tabular}

\begin{tabular}{lccccccc}
\hline & $(1)$ & $(2)$ & $(3)$ & $(4)$ & $(5)$ & $(6)$ & $(7)$ \\
2002 LSMS & 3,600 & 8,126 & 8,395 & 16,521 & 3,418 & 1,558 & 1,523 \\
2005 LSMS & 3,638 & 8,589 & 8,713 & 17,302 & 2,897 & 1,553 & 1,508 \\
2008 -09 DHS & 7,999 & 7,584 & 3,013 & 10,597 & 6,066 & 2,542 & 1,011 \\
2012 LSMS & 6,671 & 12,588 & 12,747 & 25,335 & 3,995 & 1,827 & 1,695 \\
\hline \multirow{2}{*}{ Total } & 21,908 & 36,887 & 32,868 & 69,755 & 16,376 & 7,480 & 5,737 \\
\hline \hline
\end{tabular}

Notes: Columns (1) to (5) report the number of observations as provided in the official LSMS and DHS data sets. The last two columns report the number of observations after data cleaning procedures were applied. $\left(^{*}\right)$ The age in column (7) corresponds to the women. 
Table A-2: Fraction of Households that had Another Child by Parity and Sex Composition in Albania (2002-2012) - Decomposed by Survey

\begin{tabular}{|c|c|c|c|c|c|c|c|c|}
\hline \multirow[b]{2}{*}{$\begin{array}{l}\text { Sex of first two } \\
\text { children in } \mathrm{HH} \text { with } \\
2 \text { or more children }\end{array}$} & \multicolumn{2}{|c|}{ (2002) LSMS } & \multicolumn{2}{|c|}{ (2005) LSMS } & \multicolumn{2}{|c|}{ (2008-09) DHS } & \multicolumn{2}{|c|}{ (2012) LSMS } \\
\hline & $\begin{array}{c}\text { Fraction } \\
\text { of the sample }\end{array}$ & $\begin{array}{l}\text { Fraction that } \\
\text { had another } \\
\text { child }\end{array}$ & $\begin{array}{c}\text { Fraction } \\
\text { of the sample }\end{array}$ & $\begin{array}{l}\text { Fraction that } \\
\text { had another } \\
\text { child }\end{array}$ & $\begin{array}{c}\text { Fraction } \\
\text { of the sample }\end{array}$ & $\begin{array}{l}\text { Fraction that } \\
\text { had another } \\
\text { child }\end{array}$ & $\begin{array}{c}\text { Fraction } \\
\text { of the sample }\end{array}$ & $\begin{array}{l}\text { Fraction that } \\
\text { had another } \\
\text { child }\end{array}$ \\
\hline
\end{tabular}

PanelA - Mothers aged 20 to 49 with 1 or more children younger than 18 years old

\begin{tabular}{|c|c|c|c|c|c|c|c|c|}
\hline (1) one girl & 0.489 & $\begin{array}{c}0.812 \\
(0.012)\end{array}$ & 0.480 & $\begin{array}{c}0.797 \\
(0.013)\end{array}$ & 0.503 & $\begin{array}{c}0.827 \\
(0.009)\end{array}$ & 0.495 & $\begin{array}{c}0.792 \\
(0.010)\end{array}$ \\
\hline (2) one boy & 0.510 & $\begin{array}{c}0.781 \\
(0.013)\end{array}$ & 0.519 & $\begin{array}{c}0.770 \\
(0.013)\end{array}$ & 0.496 & $\begin{array}{c}0.794 \\
(0.010)\end{array}$ & 0.504 & $\begin{array}{c}0.708 \\
(0.010)\end{array}$ \\
\hline Difference $(2)$ - (1) & $\begin{array}{c}0.020 \\
(0.022)\end{array}$ & $\begin{array}{c}0.030 \\
(0.018)^{* *}\end{array}$ & $\begin{array}{c}0.039 \\
(0.022)\end{array}$ & $\begin{array}{c}0.027 \\
(0.018)\end{array}$ & $\begin{array}{c}-0.007 \\
(0.017)\end{array}$ & $\begin{array}{c}0.032 \\
(0.013)^{* *}\end{array}$ & $\begin{array}{c}0.008 \\
(0.020)\end{array}$ & $\begin{array}{c}0.083 \\
(0.017)^{* * *}\end{array}$ \\
\hline Observations & 1956 & 1956 & 1982 & 1982 & 3135 & 3135 & 2436 & 2436 \\
\hline
\end{tabular}

Notes:* Indicates statistical significance at $10 \%{ }^{* *}$ Indicates statistical significance at $5 \% . * * *$ Indicates statistical significance at $1 \%$. 
Table A-3: Fraction of Households that had Another Child by Parity and Sex Composition in Albania (2002-2012) - Decomposed by Survey

\begin{tabular}{|c|c|c|c|c|c|c|c|c|}
\hline & $(2002)$ & LSMS & $(2005)$ & LSMS & (2008-0 & 9) DHS & $(2012)$ & LSMS \\
\hline $\begin{array}{l}\text { Sex of first two } \\
\text { children in } \mathrm{HH} \text { with } \\
2 \text { or more children }\end{array}$ & $\begin{array}{c}\text { Fraction } \\
\text { of the sample }\end{array}$ & $\begin{array}{l}\text { Fraction that } \\
\text { had another } \\
\text { child }\end{array}$ & $\begin{array}{c}\text { Fraction } \\
\text { of the sample }\end{array}$ & $\begin{array}{l}\text { Fraction that } \\
\text { had another } \\
\text { child }\end{array}$ & $\begin{array}{c}\text { Fraction } \\
\text { of the sample }\end{array}$ & $\begin{array}{l}\text { Fraction that } \\
\text { had another } \\
\text { child }\end{array}$ & $\begin{array}{c}\text { Fraction } \\
\text { of the sample }\end{array}$ & $\begin{array}{l}\text { Fraction that } \\
\text { had another } \\
\text { child }\end{array}$ \\
\hline
\end{tabular}

Panel B - Mothers aged 20 to 49 with 2 or more children younger than 18 years old

\begin{tabular}{|c|c|c|c|c|c|c|c|c|}
\hline one boy, one girl & 0.211 & $\begin{array}{c}0.378 \\
(0.026)\end{array}$ & 0.256 & $\begin{array}{c}0.329 \\
(0.023)\end{array}$ & 0.241 & $\begin{array}{c}0.371 \\
(0.019)\end{array}$ & 0.236 & $\begin{array}{c}0.326 \\
(0.022)\end{array}$ \\
\hline one girl, one boy & 0.267 & $\begin{array}{c}0.366 \\
(0.023)\end{array}$ & 0.253 & $\begin{array}{c}0.368 \\
(0.024)\end{array}$ & 0.258 & $\begin{array}{c}0.361 \\
(0.018)\end{array}$ & 0.261 & $\begin{array}{c}0.276 \\
(0.020)\end{array}$ \\
\hline two boys & 0.288 & $\begin{array}{c}0.386 \\
(0.022)\end{array}$ & 0.254 & $\begin{array}{c}0.345 \\
(0.023)\end{array}$ & 0.244 & $\begin{array}{c}0.372 \\
(0.019)\end{array}$ & 0.239 & $\begin{array}{c}0.347 \\
(0.022)\end{array}$ \\
\hline two girls & 0.231 & $\begin{array}{c}0.645 \\
(0.025)\end{array}$ & 0.235 & $\begin{array}{c}0.621 \\
(0.025)\end{array}$ & 0.254 & $\begin{array}{c}0.651 \\
(0.018)\end{array}$ & 0.262 & $\begin{array}{c}0.534 \\
(0.022)\end{array}$ \\
\hline (1) mixed combination & 0.479 & $\begin{array}{c}0.372 \\
(0.017)\end{array}$ & 0.509 & $\begin{array}{c}0.348 \\
(0.016)\end{array}$ & 0.500 & $\begin{array}{c}0.366 \\
(0.013)\end{array}$ & 0.497 & $\begin{array}{c}0.300 \\
(0.015)\end{array}$ \\
\hline (2) both same sex & 0.520 & $\begin{array}{c}0.501 \\
(0.017)\end{array}$ & 0.490 & $\begin{array}{c}0.478 \\
(0.018)\end{array}$ & 0.499 & $\begin{array}{c}0.514 \\
(0.014)\end{array}$ & 0.501 & $\begin{array}{c}0.445 \\
(0.016)\end{array}$ \\
\hline Difference (2) - (1) & $\begin{array}{c}0.041 \\
(0.025)\end{array}$ & $\begin{array}{c}0.129 \\
(0.024)^{* * *}\end{array}$ & $\begin{array}{c}0.019 \\
(0.025)\end{array}$ & $\begin{array}{c}0.129 \\
(0.024)^{* * *}\end{array}$ & $\begin{array}{c}0.000 \\
(0.019)\end{array}$ & $\begin{array}{c}0.148 \\
(0.019)^{* * *}\end{array}$ & $\begin{array}{c}0.003 \\
(0.023)\end{array}$ & $\begin{array}{c}0.145 \\
(0.022)^{* * *}\end{array}$ \\
\hline Observations & 1558 & 1558 & 1553 & 1553 & 2542 & 2542 & 1827 & 1827 \\
\hline
\end{tabular}

Notes: * Indicates statistical significance at $10 \% . * *$ Indicates statistical significance at $5 \% . * * *$ Indicates statistical significance at $1 \%$. 
Table A-4: First-Stage Specifications (Albania 2002, 2005 and 2012 LSMS)

Instruments

Dependent Variable: Fertility (Number of children ever born)

(1)

(2)

(3)

(4)

$(5)$

(6)

(7)

Panel A: Mothers aged 20 to 49 years old with 2 or more children younger than 18 years old

\begin{tabular}{|c|c|c|c|c|c|c|c|}
\hline Boy first & - & - & - & $\begin{array}{c}-0.2415^{* * * *} \\
(0.0213)\end{array}$ & $\begin{array}{c}-0.2445^{* * *} \\
(0.0261)\end{array}$ & $\begin{array}{c}-0.0262 \\
(0.0243)\end{array}$ & $\begin{array}{l}-0.0368 \\
(0.0287)\end{array}$ \\
\hline Boy second & - & - & - & $\begin{array}{c}-0.2042^{* * *} \\
(0.0215)\end{array}$ & - & - & - \\
\hline Two girls & - & - & $\begin{array}{c}0.4694^{* * *} \\
(0.0301)\end{array}$ & - & - & $\begin{array}{c}0.4296^{* * *} \\
(0.0316)\end{array}$ & $\begin{array}{c}0.4296^{* * *} \\
(0.0316)\end{array}$ \\
\hline Two boys & - & $\begin{array}{c}-0.1489^{* * *} \\
(0.0254)\end{array}$ & - & - & $\begin{array}{c}0.0209 \\
(0.0279)\end{array}$ & - & $\begin{array}{c}0.0201 \\
(0.0279)\end{array}$ \\
\hline Same sex & $\begin{array}{c}0.2320^{* * *} \\
(0.0228)\end{array}$ & - & - & $\begin{array}{c}0.2248^{* * *} \\
(0.0206)\end{array}$ & - & - & - \\
\hline R-squared & 0.1127 & 0.1003 & 0.1492 & 0.2958 & 0.2647 & 0.2958 & 0.2958 \\
\hline Observations & 4938 & 4938 & 4938 & 4862 & 4862 & 4862 & 4862 \\
\hline Survey FE & Yes & Yes & Yes & Yes & Yes & Yes & Yes \\
\hline District FE & Yes & Yes & Yes & Yes & Yes & Yes & Yes \\
\hline Controls & No & No & No & Yes & Yes & Yes & Yes \\
\hline
\end{tabular}

Panel B: Husband's of the married women with 2 or more children younger than 18 years old

\begin{tabular}{|c|c|c|c|c|c|c|c|}
\hline Boy first & - & - & - & $\begin{array}{c}-0.2444^{* * *} \\
(0.0225)\end{array}$ & $\begin{array}{c}-0.2472^{* * *} \\
(0.0276)\end{array}$ & $\begin{array}{l}-0.0211 \\
(0.0256)\end{array}$ & $\begin{array}{c}-0.0336 \\
(0.0302)\end{array}$ \\
\hline Boy second & - & - & - & $\begin{array}{c}-0.2108^{* * *} * \\
(0.0225)\end{array}$ & - & - & - \\
\hline Two girls & - & - & $\begin{array}{c}0.4782^{* * *} \\
(0.0309)\end{array}$ & - & - & $\begin{array}{c}0.4454^{* * *} \\
(0.0333)\end{array}$ & $\begin{array}{c}0.4454^{* * *} * \\
(0.0333)\end{array}$ \\
\hline Two boys & - & $\begin{array}{c}-0.1484^{* * *} \\
(0.0258)\end{array}$ & - & - & $\begin{array}{c}0.0248 \\
(0.0291)\end{array}$ & - & $\begin{array}{c}0.0237 \\
(0.0291)\end{array}$ \\
\hline Same sex & $\begin{array}{c}0.2355^{* * *} \\
(0.0232)\end{array}$ & - & - & $\begin{array}{c}0.2345^{* * *} \\
(0.0217)\end{array}$ & - & - & - \\
\hline R-squared & 0.1159 & 0.1031 & 0.1530 & 0.2839 & 0.2512 & 0.2838 & 0.2839 \\
\hline Observations & 4726 & 4726 & 4726 & 4530 & 4530 & 4530 & 4530 \\
\hline Survey FE & Yes & Yes & Yes & Yes & Yes & Yes & Yes \\
\hline District FE & Yes & Yes & Yes & Yes & Yes & Yes & Yes \\
\hline Controls & No & No & No & Yes & Yes & Yes & Yes \\
\hline
\end{tabular}

Notes: Standard errors clustered at the PSU level are in parentheses. Other covariates in the models are the following: Age, Age Squared, Age at First birth, Years of Education and also indicators for Boy 1st and Boy 2nd. The variable Boy 2nd is excluded from models in columns (5), (6) and (7). Each model is estimated with survey and district fixed effects. ${ }^{*}$ Indicates statistical significance at $10 \%$. ${ }^{* *}$ Indicates statistical significance at $5 \%$. *** Indicates statistical significance at $1 \%$. 
Table A-5: OLS and IV Estimates of Mother's Labor-Supply Models in Albania (2002 - 2012) (Mothers aged 20 to 49 years old with 2 or more children younger than 13 years old)

\begin{tabular}{|c|c|c|c|c|c|}
\hline Method & & & OLS & IV & IV \\
\hline $\begin{array}{l}\text { Instrument for Fertility: } \\
\text { (Number of children ever born) } \\
\text { Survey Fixed-Effects } \\
\text { District Fixed-Effects } \\
\text { Controls }\end{array}$ & & & $\begin{array}{l}- \\
\text { Yes } \\
\text { Yes } \\
\text { Yes }\end{array}$ & $\begin{array}{c}\text { Same-sex } \\
\text { Yes } \\
\text { Yes } \\
\text { Yes }\end{array}$ & $\begin{array}{c}\text { Two girls } \\
\text { Yes } \\
\text { Yes } \\
\text { Yes }\end{array}$ \\
\hline Dependent variable & Mean & Obs. & $(1)$ & $(2)$ & $(3)$ \\
\hline \multicolumn{6}{|c|}{ Panel A: All databases (LSMS and DHS) } \\
\hline Worked in last 7 days & 0.409 & 4390 & $\begin{array}{c}-0.0263^{* *} \\
(0.0115)\end{array}$ & $\begin{array}{c}0.1114 \\
(0.0801)\end{array}$ & $\begin{array}{c}0.0590 \\
(0.0570)\end{array}$ \\
\hline Worked off-farm & 0.144 & 4390 & $\begin{array}{c}-0.0265^{* * *} \\
(0.0071)\end{array}$ & $\begin{array}{c}0.0695 \\
(0.0568)\end{array}$ & $\begin{array}{c}0.1047^{* *} \\
(0.0430)\end{array}$ \\
\hline Worked on-farm & 0.211 & 4390 & $\begin{array}{c}0.0133 \\
(0.0100)\end{array}$ & $\begin{array}{c}0.0052 \\
(0.0642)\end{array}$ & $\begin{array}{c}-0.0266 \\
(0.0441)\end{array}$ \\
\hline Self-employed & 0.056 & 4390 & $\begin{array}{c}-0.0068 \\
(0.0053)\end{array}$ & $\begin{array}{c}0.0763^{*} \\
(0.0412)\end{array}$ & $\begin{array}{c}0.0030 \\
(0.0269)\end{array}$ \\
\hline \multicolumn{6}{|c|}{ Panel B: Only LSMS databases } \\
\hline Hours per week (total) & 15.34 & 2949 & $\begin{array}{c}-0.4517 \\
(0.5889)\end{array}$ & $\begin{array}{c}12.0095^{* *} \\
(5.1338)\end{array}$ & $\begin{array}{c}7.8316^{* *} \\
(3.3599)\end{array}$ \\
\hline Hours per week (off-farm) & 6.356 & 2949 & $\begin{array}{c}-1.3845^{* * *} \\
(0.4208)\end{array}$ & $\begin{array}{l}6.6192^{*} \\
(3.6856)\end{array}$ & $\begin{array}{c}7.5173^{* * *} \\
(2.5979)\end{array}$ \\
\hline Hours per week (on-farm) & 7.295 & 2949 & $\begin{array}{c}1.5401^{* * *} \\
(0.4834)\end{array}$ & $\begin{array}{c}1.7394 \\
(3.5686)\end{array}$ & $\begin{array}{l}-0.8690 \\
(2.1904)\end{array}$ \\
\hline Hours per week (self) & 2.111 & 2949 & $\begin{array}{c}-0.2615 \\
(0.2792)\end{array}$ & $\begin{array}{l}4.8982^{*} \\
(2.6642)\end{array}$ & $\begin{array}{c}1.2340 \\
(1.6549)\end{array}$ \\
\hline Second occupation & 0.014 & 2949 & $\begin{array}{c}0.0078^{*} \\
(0.0047)\end{array}$ & $\begin{array}{c}0.0314 \\
(0.0291)\end{array}$ & $\begin{array}{c}0.0032 \\
(0.0197)\end{array}$ \\
\hline Monthly Labor Income & 43824.28 & 2949 & $\begin{array}{c}-6365.61^{* * *} \\
(2321.12)\end{array}$ & $\begin{array}{c}54116.80^{* *} \\
(24697.23)\end{array}$ & $\begin{array}{c}39320.05^{* *} \\
(16289.33)\end{array}$ \\
\hline
\end{tabular}

Notes: Standard errors clustered at the PSU level are in parentheses. All the models include the following covariates: Age, Age Squared, Age at First birth and Years of Education. IV Models in columns (2) and (3) also include indicators for Boy 1st and Boy 2nd. Each model is estimated with survey and district fixed effects. * Indicates statistical significance at $10 \%$. ** Indicates statistical significance at $5 \%$. *** Indicates statistical significance at $1 \%$. 